\title{
Review Article \\ Enhancing the Migration Ability of Mesenchymal Stromal Cells by Targeting the SDF-1/CXCR4 Axis
}

\author{
Leah A. Marquez-Curtis ${ }^{1}$ and Anna Janowska-Wieczorek ${ }^{1,2}$ \\ ${ }^{1}$ Canadian Blood Services, Research and Development, Edmonton, AB, Canada \\ ${ }^{2}$ Department of Medicine, University of Alberta, CBS Building, 8249-114 Street NW, Edmonton, AB, Canada T6G 2R8 \\ Correspondence should be addressed to Anna Janowska-Wieczorek; anna.janowska@blood.ca
}

Received 16 August 2013; Revised 9 October 2013; Accepted 28 October 2013

Academic Editor: Ulrich Kneser

Copyright (C 2013 L. A. Marquez-Curtis and A. Janowska-Wieczorek. This is an open access article distributed under the Creative Commons Attribution License, which permits unrestricted use, distribution, and reproduction in any medium, provided the original work is properly cited.

\begin{abstract}
Mesenchymal stromal cells (MSCs) are currently being investigated in numerous clinical trials of tissue repair and various immunological disorders based on their ability to secrete trophic factors and to modulate inflammatory responses. MSCs have been shown to migrate to sites of injury and inflammation in response to soluble mediators including the chemokine stromal cellderived factor-(SDF-)1, but during in vitro culture expansion MSCs lose surface expression of key homing receptors particularly of the SDF-1 receptor, CXCR4. Here we review studies on enhancement of SDF-1-directed migration of MSCs with the premise that their improved recruitment could translate to therapeutic benefits. We describe our studies on approaches to increase the CXCR4 expression in in vitro-expanded cord blood-derived MSCs, namely, transfection, using the commercial liposomal reagent IBAfect, chemical treatment with the histone deacetylase inhibitor valproic acid, and exposure to recombinant complement component Clq. These methodologies will be presented in the context of other cell targeting and delivery strategies that exploit pathways involved in MSC migration. Taken together, these findings indicate that MSCs can be manipulated in vitro to enhance their in vivo recruitment and efficacy for tissue repair.
\end{abstract}

\section{Introduction}

Ever since the identification of a rare population of multipotent nonhematopoietic cells in the bone marrow [1], which have been later termed mesenchymal stromal cells (MSCs), there has been an enormous rise in the number of publications pertaining to these cells. Research efforts have focused not only on elucidating the biological properties of MSCs but also on developing approaches for MSCbased therapies. To date there are nearly 400 clinical trials in which MSCs are investigated as therapy for a diverse range of diseases (http://www.clinicaltrials.gov/), particularly orthopedic, autoimmune, and ischemic disorders [2, 3]. Although originally isolated from bone marrow, MSCs have since been obtained from a variety of adult and neonatal tissues including placenta, umbilical cord, Wharton's jelly, and cord blood $[4,5]$. Lacking unique markers, MSCs have been defined by criteria based on their propensity to adhere to plastic, expression of CD73, CD90, and CD105, and the absence of CD34, CD45, CD14, and HLA-DR and by their trilineage differentiation into adipocytes, chondrocytes, and osteocytes [6]. Despite similar phenotypic and cytological characteristics, MSCs from diverse sources exhibit significant differences in the expression of regulatory proteins involved in cell viability, engraftment, and migration $[7,8]$. Because of the ability of MSCs to differentiate into bone and cartilage, their clinical application in musculoskeletal regeneration is actively being explored [3]. However, while there are claims of their potential to differentiate into hepatocytes and neurons $[9,10]$, solid evidence of differentiation that transcends the germ-layer boundaries remains scarce [11, 12]. The therapeutic efficacy of MSCs appears to be derived from their ability to secrete a wide array of bioactive molecules that are immune-modulatory, antiapoptotic, anti-inflammatory, proangiogenic, chemotactic, or stimulatory of tissue regeneration [13-19]. As MSC migration and recruitment are crucial 
to the success of MSC-based therapies, the purpose of this review is to appraise current investigations on the migration of MSCs to sites where they are needed.

Because MSCs can be found, albeit in small numbers, in almost all tissues where they play a role in maintaining homeostasis, it has been proposed that therapeutic efforts should focus on maximizing the mobilization of endogenous MSCs within patients to take advantage of their intrinsic regenerative potential $[20,21]$. In this review, we will first briefly discuss how endogenous MSCs respond to signals of cellular damage and contend that therapy using endogenous MSCs for in situ regeneration becomes inadequate in patients with late-stage disease or severe injury and in those who are older; therefore, we will focus on administration of exogenous MSCs. Despite their innate ability to migrate to sites of injury or inflammation, the homing process of MSCs can be inefficient due to limitations in the cellular signals that regulate their trafficking. In fact, the majority of infused MSCs fail to reach the site of injury and consequently only minimal therapeutic benefit has been demonstrated in clinical trials $[22,23]$. We will also summarize existing evidence of the biodistribution of MSCs after infusion based on current cell tracking techniques. As MSCs exhibit a wide array of chemokine and adhesion receptors that are involved in their migration, we will also describe cell manipulation approaches that target ligand/receptor interactions directing MSCs to sites of injury and characterize molecular signalling pathways governing MSC homing.

A number of studies have shown that the chemokine stromal cell-derived factor-1 (SDF-1, also known as CXCL12) is critical for stem/progenitor and mesenchymal cell chemotaxis and organ-specific homing in injured tissue through interaction with its cognate receptor CXC chemokine receptor 4 (CXCR4) on the surface of these cells (reviewed in [2427]). Although CXCR4 is highly expressed by MSCs within the bone marrow, its expression is markedly reduced during ex vivo expansion of MSCs [28, 29], which decreases their ability to respond to homing signals emanating from injured sites. In this review we will describe strategies proposed by us and others to enhance the migration ability of systemically infused exogenous MSCs.

\section{Mobilization of Endogenous MSCs versus Exogenously Administered MSCs}

Tissue repair is an essential mechanism for maintaining the integrity and function of the human body as it is frequently exposed to physical insults that may damage various tissues and organs. Within minutes of injury, several types of inflammatory cells including neutrophils, monocytes, and lymphocytes rush to the damaged site and secrete a broad spectrum of cytokines and growth factors that attract other cells residing in tissue and in circulation. Endogenous MSCs are mobilized and contribute to tissue repair by acting as a reservoir of cells for regeneration [30, 31] and guarding against inflammation [32]. MSCs communicate with other cells in the human body and appear to "home" to areas of injury in response to signals of cellular damage (reviewed in [33]). MSCs themselves produce a variety of molecules that provide further cues for regenerative pathways, allowing MSCs in niches throughout the body to support other cell populations and contribute to tissue repair [12, 34, 35]. As such, endogenous MSC homing is being exploited as a therapeutic option because it does not require extensive ex vivo cell manipulation or vehicles for delivery. Approaches currently under development include use of chemokines and other chemotactic factors to recruit a sufficient number of endogenous MSC to effect tissue regeneration and/or colonize biomaterial scaffolds (reviewed in $[21,36]$ ). However, in reality the reservoirs of MSCs can be depleted by degenerative disease, physiological aberrations, or age. In fact, it has been shown that the number of human MSCs obtained by marrow aspiration declines with age and that there is an age-related decline in overall suitability of endogenous MSCs for cellbased therapies [37]. Defects in tissue repair constitute a severe health problem and are frequently seen not only in older individuals but in patients with diabetes, those receiving chemo- or radiotherapy, and other patients whose immune system is suppressed (reviewed in [38]). In such cases, administration of exogenous MSCs could be a viable alternative to harnessing the limited number of circulating endogenous MSCs.

The route of administration of exogenous MSCs is an important factor in determining their fate. Local or sitedirected delivery of MSCs has recently been shown as beneficial in certain settings, such as the intra-articular injection of autologous MSCs in patients with knee osteoarthritis [39]. Also, intramyocardial injection of MSCs has been the most widely used route of delivery into infarcted myocardium. For example, local direct intra-myocardial injections of autologous MSCs administered to patients with coronary artery disease and refractory angina have resulted in significant improvements in clinical parameters [40]. However, although this technique guarantees localised delivery to the inflamed tissue, it has restricted clinical applicability because it is invasive and can lead to cardiac arrhythmias [41].

Systemic delivery of exogenous MSCs in contrast provides not only a minimally invasive alternative, but also enables the delivery of multiple doses of ex vivo expanded cells and ensures that the cells remain in proximity to blood vessels rich in oxygen and nutrients. Systemic infusion also allows MSCs to exert their immune-modulatory effects in the context of inflammatory-mediated disorders [22, 42, 43]. It is now recognized that MSCs participate in immune surveillance and exert pleiotropic effects on both adaptive and innate immune systems $[44,45]$. The first MSC-based drug approved for market, Prochymal, which consists of human bone marrow-derived MSCs, is intravenously administered to pediatric patients with acute graft-versus-host disease to modulate adverse immune and inflammatory responses [46]. However, it has been realized that during intravenous delivery there is a loss of MSCs in the vasculature, mostly in the lungs and liver [33,47]. Alternatively, MSCs passively arrest 
and interrupt blood flow during the first pass through the precapillary vessels thus preventing the majority of infused MSCs from homing to damaged or diseased tissues [48]. Understanding the biodistribution of transplanted MSCs is essential for designing protocols for the efficient delivery of MSCs to sites of inflammation and injury.

\section{Tracking the Migration of MSC}

In view of the lack of MSC-specific markers, sophisticated detection systems and novel animal models are being explored for a detailed analysis of MSC homing and engraftment in vivo including in situ hybridization, fluorescence labelling, radioactive labelling, immunofluorescence, and bioluminescence. Green fluorescent protein (GFP) was used to track the distribution and fate of MSCs for at least 28 days after local delivery to rat hearts with myocardial infarction [49]. MSCs constitutively expressing red fluorescence were radioactively labeled with ${ }^{51} \mathrm{Cr}$ and infused into mice; these MSCs were shown to have short-term survival and scarce distribution beyond the lungs [47]. In contrast, MSCs labeled with iron oxide nanoparticles and tracked by magnetic resonance imaging displayed preferential migration and subsequent engraftment in the thymus as well as the gastrointestinal tract but not the lungs [50]. In another study, MSCs labelled with ${ }^{111}$ In-oxine were shown to be largely localised in pulmonary capillaries and survived only transiently [51]. Bone marrow-derived MSCs from GFP transgenic male mice were transfused to female mice which were inflicted with burn wounds; thereafter, Y chromosomepositive cells were shown to be present in the injured sites by fluorescence in situ hybridization [52]. Thus, evidence is accumulating that some MSCs eventually reach sites of injury where they exert their potential for tissue repair.

Several studies have demonstrated beneficial effects of intravenous MSCs in a variety of disease models despite their low engraftment rate. Five out of six children with osteogenesis imperfecta had clinical improvement of $60 \%$ to $94 \%$ even though engraftment did not exceed $1 \%$ [53]. Intravenous infusion of MSCs three hours after acute myocardial infarction in mice resulted in a reduced infarct size and a slight improvement in the left ventricular function one month later, although after 24 hours only approximately $3 \%$ of injected MSCs were found mostly in the border zone of infarcted myocardium [54]. Systemic infusion of adipose-derived MSCs significantly reduced the severity of experimental arthritis even when MSCs were no longer present [55]. In mice infused with bone marrow-derived luciferase-labelled MSCs, peak luminescence persisted in the liver $24 \mathrm{~h}$ after reperfusion, after which luciferase activity gradually declined; nevertheless, remnant liver regeneration rate was accelerated relative to the control group [56].

Attempts have been made to enhance recruitment by increasing the dose of MSCs infused. Although the optimal dosage of MSCs for their use in therapeutic applications is still unclear and should be dependent upon the type of cell therapy, at least 1 to $2 \times 10^{6}$ MSCs per $\mathrm{kg}$ of patient body weight is generally used [30]. In fact, given the low engraftment rate of MSCs, a dose ranging from 150 million to 300 million cells administered twice per week over the course of two weeks is usually used in clinical trials [57]. The high dose required for clinical application of MSCs entails extensive in vitro expansion, which has been shown to cause enlargement of cells [58]. This could explain the observation in a rat model that a large fraction of systemically infused MSCs becomes massively entrapped within the lungs and filtering organs as emboli $[19,59]$. As the numbers of primary MSCs which can be isolated are too low for clinical use, it is necessary to expand MSCs in culture, and significant progress has been made to generate various culture media formulations to replace ill-defined serum and human-sourced supplements [60].

However, the possibility exists that the MSC phenotype and biological properties vary between in vivo and in vitro settings due to removal from their natural environment and the use of chemical and physical growth conditions that might alter their characteristics. MSCs are known to undergo phenotypic rearrangements during ex vivo manipulations, losing expression of some markers while also acquiring new ones [34]. Microarray analysis revealed that gene expression profiles of ex vivo expanded MSCs were mainly influenced by the level of cell confluence rather than initial seeding density, and the genes that were upregulated in MSCs are involved in chemotaxis, inflammation, and immune responses [61]. Different cell sources and culture conditions are also likely to affect the MSC phenotype and hence their migratory patterns [7]. For example, freshly isolated, uncultured MSCs have been reported to migrate to bone marrow and spleen after systemic transplantation in experimental animal models. In contrast, culture-expanded MSCs appear unable to migrate and home to the bone marrow $[57,62,63]$. Whereas tracking studies have shown that the majority of MSCs immediately localize to the lungs after intravenous infusion, they tend to disappear from the lungs within hours and migrate to other tissues, such as the liver, spleen and kidney, and preferentially to sites of injury or tumours $[51,59,64,65]$. Despite the fact that the endothelium is functionally different in various tissues, in general MSCs follow a multistep homing cascade (activation, adhesion and transmigration) to migrate across the endothelium, which is similar to that employed by leukocytes migrating to sites of inflammation [66-68] (Figure 1). MSCs express a variety of cell adhesion molecules and homing receptors. However, the apparent lack of MSC rolling had been attributed to the absence of selectin receptors [69]. The release of inflammatory cytokines triggers the activation of vascular cell adhesion molecule (VCAM)-1 expressed by endothelial cells and $\alpha_{4} \beta_{1}$ integrin (VLA-4) expressed by MSCs. Tissue injury and inflammation stimulate the secretion of various growth factors and chemokines such as SDF-1 which interacts with the 7-transmembrane G-coupled receptor CXCR4 on the surface of MSCs. Finally, the activation of proteases, particularly matrix metalloproteinase(MMP-) 2 and membrane type (MT)1-MMP expressed by MSCs, facilitates transmigration across extracellular matrix in the basement membrane. 


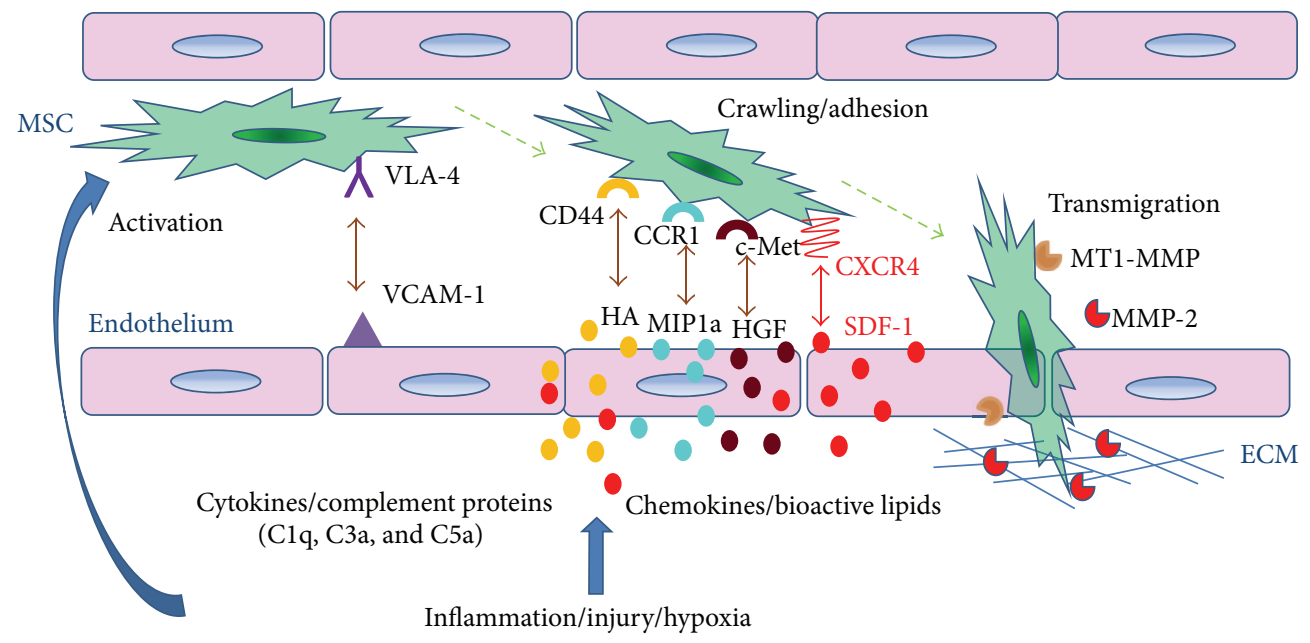

FIGURE 1: Mechanisms of MSC transendothelial migration towards injured tissue. Mesenchymal stromal cells (MSCs) express the $\alpha_{4} \beta_{1}$ integrin very late antigen (VLA)-4, and endothelial cells express the corresponding ligand, vascular cell adhesion molecule (VCAM)-1. The onset of inflammation in injured tissue causes the release of cytokines which upregulate VCAM-1 and activates VLA-4, leading to initial arrest of MSC on the endothelium surface. MSCs also express a variety of homing receptors including CXCR4, CD44, CCR1, and c-Met, and their corresponding ligands, namely SDF-1, hyaluronic acid, M1P-1(alpha), and HGF, respectively, are upregulated at the site of tissue injury and/or hypoxia. These ligand-receptor interactions, as well as chemotactic bioactive lipids, modulate cell-cell contact between MSCs and endothelia cells. In addition, complement proteins that are stimulated by inflammation such as Clq, C3a, and C5a also chemoattract MSCs. Moreover, MSCs express the extracellular matrix-degrading enzymes, matrix metalloproteinase-(MMP-) 2 and membrane type (MT)1-MMP that play a role in their extravasation.

\section{Chemotactic Factors That Promote Tropism of MSCs to Sites of Injury}

MSCs show a propensity to migrate to sites of tissue injury, such as to ischemic brain [70], infarcted myocardium $[25,71]$, demyelinated lesions [72], pulmonary fibrosis [73], laserinduced ocular damage and injured corneal epithelium [74, 75], kidney after ischemic reperfusion [76], and injured liver [64]. MSCs have the ability to traffic into inflamed tissues; however, their migratory mechanisms need to be elucidated before this can be exploited therapeutically. The mode of recruitment of MSCs is by chemotaxis, the directional migration in response to a gradient of soluble chemoattractants (growth factors and chemokines), as well as other factors. MSCs have been reported to express various chemokines and chemokine receptors with differences in expression likely due to isolation techniques and in vitro culture conditions $[25,29$, $77,78]$. In fact, analysis of chemokine receptors in short-term and long-term murine MSC cultures showed tissue culturedependent expression of several receptors [79]. Also, ex vivo expanded human bone marrow MSCs showed differences in the gene expression patterns of factors that play a critical role in cell migration and tissue regeneration according to the seeding density and culture time [80]. Over 40 regulatory cytokines were detected in the conditioned medium obtained from murine MSCs [51].

After culturing MSCs for 48 hours, elevated levels of monocyte chemoattractant protein-1 (MCP-1), macrophage inflammatory protein-1 (MIP-1) $\alpha$, and MIP- $1 \beta$ were found compared to control media, and MCP-1 and MIP- $1 \alpha$ increased the migration of MSCs [14]. Consistent with this finding, intravenously infused allogeneic eGFP ${ }^{+}$MSCs migrated preferentially toward the heart of mice overexpressing MCP-1 compared with wild-type animals, in which migration toward heart was negligible [81]. Moreover, human MSCs migrated in response to chemokines known to be expressed in the lesions of multiple sclerosis, namely, SDF-1, MCP-1, RANTES, MIP-1 $\alpha$, and IP-10 [72], and to IL- 8 which is highly expressed in gliomas [82].

The growth factor receptors for bone morphogenetic protein, epidermal growth factor, transforming growth factor, fibroblast growth factor (FGF), hepatocyte growth factor (HGF), insulin-like growth factor (IGF), platelet-derived growth factor (PDGF), and vascular endothelial growth factor (VEGF), chemokine receptors for MIP, RANTES, MCP, TARC, MDC, and SDF, and receptors for tumour necrosis factor, lysophosphatidic acid, spingosine-1-phosphate, and Toll-like receptor are expressed by bone marrow-derived MSCs [36]. In particular, the CC chemokine receptors 1 and 2 (CCR-1 and CCR-2) play a crucial role in the migration and engraftment of bone marrow-derived MSCs into ischemic myocardial tissue [25]. The chemokine receptors, namely CXCR4, CX3CR1, CXCR6, CCR1, and CCR7, expressed by a minority $(2 \%-2.5 \%)$ of human bone marrow-derived MSCs, were linked to the in vivo migratory abilities of MSCs toward murine pancreatic islets [83]. Overexpression of CCR1 in murine MSCs increased their migration to infarcted myocardium and reduced infarct size and cardiomyocyte apoptosis [84].

Previously we showed that MSCs also express c-met, the receptor for HGF [28], whose concentration is upregulated in wound areas and shown to act as chemoattractant for MSCs [28]. HGF also mediated migration of MSCs to sites of apoptotic cell death and towards HGF-expressing 
glioblastomas, and this observation has been exploited in gene therapy to deliver therapeutic drugs to the tumor cells [85]. In this regard, fibrin or collagen gels loaded with HGF were used as a recruitment system for endogenous MSC to facilitate wound healing [86].

MSCs also express CD44, the receptor for hyaluronic acid, which accumulates in the kidney following ischemic injury. CD44-deficient MSCs or MSCs incubated with a CD44 blocking antibody did not migrate to kidney with glycerol-induced damage; on the other hand, transfection of MSCs with CD44 restored their recruitment to injured kidney [87].

In addition to chemotactic peptides, bioactive lipids have recently been implicated in the recruitment of MSCs. For example, ceramide-1-phosphate was shown to be upregulated in damaged tissues and to provide chemotactic homing signals to bone marrow-derived MSCs [88]. MSCs have also been shown to interact with immune cells during inflammation, and these interactions may impact the way MSCs contribute to tissue repair $[44,45]$. The complement cascade (activated through the classical, alternative, or lectin pathway) leads to the generation of bioactive peptides such as $\mathrm{C} 3 \mathrm{a}$ and $\mathrm{C} 5 \mathrm{a}$ that are responsible for chemoattracting immune cells to sites of inflammation [89]. Although it has been shown that C3a and C5a chemoattract human MSCs [90], recently we reported that the initiator of the classical pathway, complement component 1 subcomponent q (Clq) also exerts a chemotactic effect on them [91].

Microvesicles released by MSCs have also been recently appreciated for their role in recruiting MSCs and tissue repair $[18,92,93]$. These membrane-derived microvesicles have the ability to transfer lipids, nucleic acids, and proteins (e.g., receptors such as CXCR4) to neighboring cells, thereby mediating a variety of biological responses such as selfrenewal, differentiation, adhesion, and migration [93, 94]. The SDF-1/CXCR4 axis has been shown to be significantly upregulated in many experimental models of tissue injury such as myocardial infarction [95-97], ischemic brain lesion [70], acute kidney injury [98], and burn wounds [52].

\section{The SDF-1/CXCR4 Axis in MSC Migration}

It is generally believed that SDF-1 mediates cell migration through its binding with CXCR4. Therefore, the enhanced secretion of SDF-1 at the site of injury creates an environment facilitating the homing of circulating CXCR4-positive cells. MSCs stimulated with SDF-1 showed 30 differentially expressed genes, 11 of which are involved in cellular movement [99]. The SDF-1/CXCR4 pathway is crucial in the migration of MSCs to bone fractures, as MSC recruitment was abrogated when SDF-1 signalling was impaired [100]. CXCR7, another chemokine receptor, has also been shown to bind SDF-1 with high affinity [101]; however, the activation of CXCR7 by SDF-1 does not contribute to cell chemotaxis $[102,103]$. Consistently, MSC migration to ischemic kidney was shown to be mainly CXCR4-dependent, as confirmed by the increased migration of CXCR4-transduced MSCs and full inhibition of MSC migration using the CXCR4 antagonist
AMD3100 $[98,104]$. This is in contrast to a report showing that the overexpression of CXCR4 did not improve MSC homing in a mouse model of cisplatin-induced acute kidney injury [105]. More evidence is emerging on the important role of the SDF-1/CXCR4 in the recruitment of MSCs into injury sites in animal models [24, 26, 27, 52, 95, 97, 104].

GFP-labelled MSCs were transplanted intravenously with or without treatment with CXCR4-blocking antibody into rats that had unilateral mandibular distraction osteogenesis, and their distribution in the soft callus was examined after $24 \mathrm{~h}$. SDF-1 facilitated the migration of MSCs both in vitro and in vivo, and this migration was inhibited by AMD3100 [106]. Furthermore, migration to burn wounds in mice promoted the epithelialization of the wound, whereas pretreatment of the MSCs with AMD3100 attenuated wound closure [52]. In mice with acute myocardial infarction, the local trophic effects of infused MSCs required cardiac myocyte (CM)-CXCR4 expression and were mediated by SDF-1 secretion. In the absence of CM-CXCR4 expression, there was a significant loss of functional benefit in MSC-mediated repair despite equal increases in vascular density [71]. In another study, MSCs were transduced using lentiviral vectors to overexpress the CXCR4-eGFP fusion protein and injected into rats following a left middle cerebral artery occlusion. The number of eGFP-positive cells surrounding the occlusion areas was significantly increased in the CXCR4-MSC-treated group compared to the control group; moreover, they showed an increase in the capillary vascular volume of the peri-infarct area, a reduction in the volume of the cerebral infarction, and improved neurological function [107]. Taken together, these studies confirm that the interaction between locally produced SDF-1 and its receptor CXCR4 expressed on the surface of MSCs plays a crucial role in the homing of transplanted cells. However, culture-expanded MSCs show a downregulation of surface expression of key homing receptors including CXCR4 $[29,108]$ and their ability to respond to homing signals. Hence various strategies have been explored and employed to enhance the expression of CXCR4 in MSCs.

\section{Preconditioning or Engineering MSCs before Infusion to Improve Cell Migration}

Several groups have attempted to develop alternative approaches to optimize MSC migration efficiency and potentiate their beneficial effect at the site of the injury by preconditioning MSCs before infusion with various compounds (e.g., drugs and/or growth factors) possessing prosurvival and pro-migratory properties, by certain physical treatments (e.g., hypoxia) (reviewed in [109]), or by cellular modification (reviewed in [110]). Specifically, MSCs have been conjugated with ligands (e.g., Sialyl Lewis ${ }^{\mathrm{x}}$ ) that mediate cell rolling, adhesion, and transmigration to inflamed tissue [111]. Also, coating MSCs with antibodies against vascular cell adhesion molecule and addressins enhanced their delivery to inflamed colon in a mice model of inflammatory bowel disease [112]. Genetically modified MSCs expressing P-selectin glycoprotein ligand -1 and Sialyl-Lewis ${ }^{\mathrm{x}}$ exhibited robust rolling leading to increased homing in injured ear; 
further transfection with IL-10 significantly improved the anti-inflammatory impact of these cells [113].

In recognition of the fact that aging reduces the number of MSCs that can differentiate into osteoblasts, leading to impairment of osteogenesis, it has been proposed that if MSCs could be directed toward the bone surface, they could be a viable therapeutic option for bone regeneration. To this end MSCs have also been conjugated to a synthetic peptidomimetic ligand (LLP2A) that has high affinity for activated $\alpha_{4} \beta_{1}$ integrin in order to direct the transplanted MSCs to bone. This treatment significantly increased the rate of bone formation and restored both trabecular and cortical bone loss induced by estrogen deficiency or advanced age in mice [114].

Preconditioning with insulin-like growth factor-(IGF-) 1 improved the migration capacity of MSCs and restored normal renal function after acute kidney injury through a mechanism involving the upregulation of CXCR4. Its functional role was further confirmed by blocking CXCR 4 which totally abrogated the pro-migratory effect of IGF-1 on MSCs [115]. In a rat model of myocardial infarction MSCs treated with a combination of IGF-1, fibroblast growth factor-2 and bone morphogenic protein-2 showed enhanced expression of cardiac transcription factors [116]. In a mouse model of osteogenesis imperfecta, priming human fetal MSCs with SDF-1 upregulated surface CXCR4 expression and enhanced in vitro chemotaxis, which translated to increased in vivo engraftment in the bone and bone marrow, improved bone quality and plasticity, and a trend to lower fracture rate [117].

Treatment with inhibitors of glycogen synthase kinase$3 \beta$ (GSK-3 $\beta$ ) increased the levels of CXCR4 and matrix metalloproteinase (MMP)-2 and membrane type (MT)1-MMP [118], which we have shown to be involved in MSC migration [28]. In another study, EPO combined with G-CSF enhanced MMP-2 expression in MSCs, promoted MSC motility, and activated the extracellular signal related kinase (ERK)1/2 signaling pathway [119]. Preconditioning MSCs with oxytocin (OT) have also been proposed as a novel strategy for enhancing therapeutic potential of these cells in ischemic heart because, following OT treatment, MSCs respond with rapid calcium mobilization and upregulation of the protective protein kinase $\mathrm{B}$ (PKB or Akt), phospho-ERK1/2 proteins and genes with angiogenic and antiapoptotic properties, such as vascular endothelial growth factor, thrombospondin, tissue inhibitors of metalloproteinase-(TIMP-) 1, TIMP-2, TIMP3, and MMP-2 [120]. In a related study, two constituents of traditional Chinese herbal medicine (tanshinone IIA and astragaloside IV) were shown to increase CXCR4 expression, in vitro migration, and the capacity of MSCs to home to rat ischemic myocardium [121]. Previously, we reported that a histone deacetylase inhibitor, valproic acid (VPA), increases CXCR4 expression on CD34+ HSPCs derived from cord blood and their migration towards an SDF-1 gradient [122]. We therefore investigated the effect of VPA on the migration of MSCs as we will discuss below.

Various pathologies compromise tissue reperfusion and thereby decrease tissue oxygen tension. Based on the fact that the bone marrow niche has a low oxygen tension (1$7 \%)$, hypoxic pre-conditioning during ex vivo expansion has been widely studied and shown to also have a beneficial effect on stem cell migration. Several reports have shown that short-term exposure of MSCs to hypoxia could increase their migration. The migration capacity of MSCs was improved at very low oxygen concentrations (1\%) via upregulation of hypoxia-inducible factor- $1 \alpha$ [123]. Hypoxic-treated MSCs were selectively recruited to ischemic kidneys in response to SDF- $1 \alpha$, and this increased chemotaxis was blocked by an anti-CXCR4 antibody but not by an anti-CXCR7 antibody [102]. Lastly, human MSCs grown under low $\mathrm{O}_{2}(5 \%$, hypoxic) demonstrated markedly higher targeted migration activity towards wound healing cytokines such as those found in ischemic and myocardial infarcts compared to those grown under normal $\mathrm{O}_{2}(21 \%$, normoxic) [124].

Aside from molecular and physiological conditioning, physical stimuli have also been exploited to direct the migration of MSCs. As naturally occurring electric fields exist during healing at sites of bone fracture, by culturing MSCs in direct electrical current MSC migratory response was increased [125]. Pulse-focused ultrasound has also been shown to upregulate chemoattractants and enhance the homing, permeability, and retention of human MSCs [126]. Low-level shear stress has been employed to induce MSC migration in a wound model through upregulated secretion of SDF-1 and increased CXCR4 expression [127]. Similarly, mechanical stretching of skin induced temporal upregulation of SDF- $1 \alpha$ and increased the in vitro and in vivo migration of MSCs, which was significantly blocked by AMD3100, confirming the crucial role of the CXCR4 receptor [128]. In this regard, several approaches have been explored to enhance the expression of CXCR4, and we describe below the strategies employed by our group.

\section{In Vitro Approaches to Enhance MSC Migration through CXCR4 Upregulation}

7.1. IBAfect-Transfection of CXCR4. Currently, the most widely used method to transfer genes into MSCs is through viral delivery vectors, and several groups have attempted to overexpress CXCR4 on MSCs in this manner. Adenoviral, retroviral, and lentiviral transduction of CXCR4 have been shown to increase mobilization and engraftment of MSCs in animal models of injury [107, 129-131]. However, there is increased interest in developing safe and efficient nonviral gene delivery systems to reduce the risks of mutagenesis due to the random integration of viral genes into the host genome and the immunogenicity of the virus itself. Nucleofection has been proposed as a technique that combines an easy protocol with high effectivity and basically allows in vivo application according to Good Manufacturing Practices guidelines [132].

Cationic liposomal delivery has emerged as another viable alternative to gene therapy using viral vectors because of its low toxicity, lack of immunogenicity after in vivo administration, low cost, and relative ease in creating nucleic acid/liposome complexes on a large scale for clinical use [133]. Previously, we reported CXCR4 gene delivery into 
(a) IBAfect-transfection

(b) Valproic acid priming

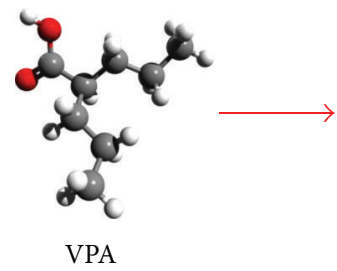

(c) C1q priming
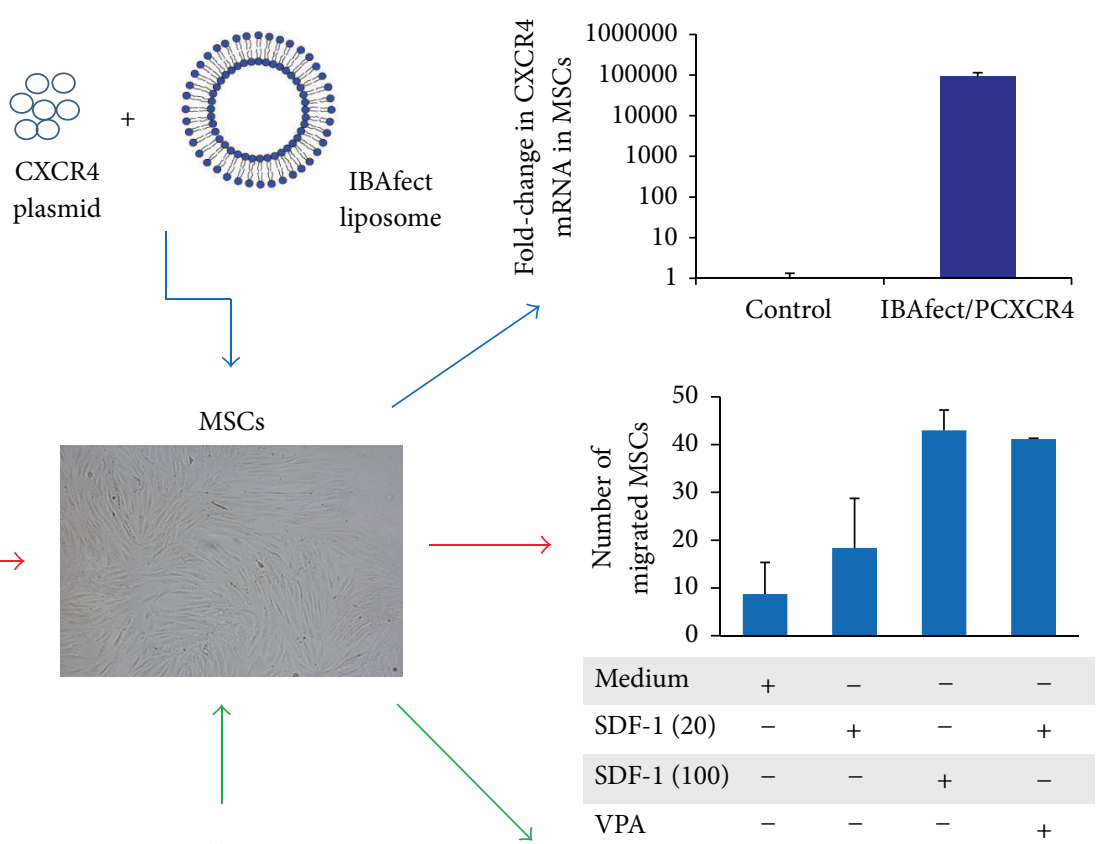

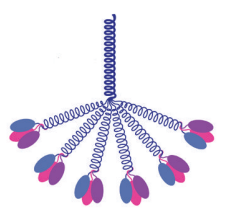

$\mathrm{C} 1 \mathrm{q}$
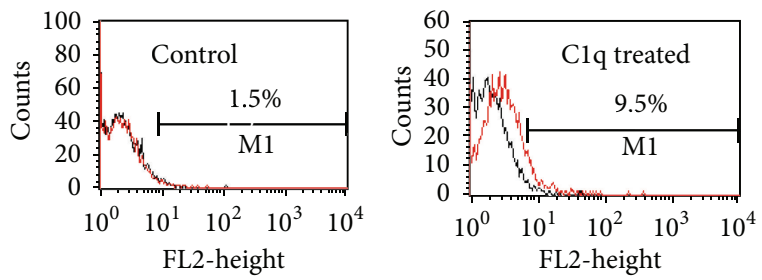

CXCR4 expression

FIgURE 2: Approaches to enhance MSC migration by upregulating CXCR4. Cord blood-derived mesenchymal stromal cells (MSCs) were subjected to three treatments. (a) Transfection with CXCR4 plasmid using the liposomal reagent IBAfect led to a $10^{5}$-fold increase in CXCR4 mRNA expression. (b) Priming MSCs with $5 \mathrm{mM}$ valproic acid (VPA) increased trans-Matrigel chemoinvasion towards a low SDF-1 gradient $(20 \mathrm{ng} / \mathrm{mL})$ to a level comparable to that of untreated cells migrating towards a high SDF-1 gradient (100 ng/mL). (c) Exposure of MSCs to $10 \mu \mathrm{g} / \mathrm{mL} \mathrm{Clq}$ also primed/enhanced trans-Matrigel migration towards SDF-1 and this was accompanied by over 6-fold increase in the surface expression of CXCR4 in Clq-treated cells.

human HSPCs using IBAfect, a polycationic liposomal transfection reagent, and achieved up to $20 \%$ transfection [134]. The specifically designed molecular structure of IBAfect ensures easy entry of plasmid DNA into cells by forming a compact complex with the lipid. We found that IBAfectmediated CXCR4 transfection of cord blood-derived MSCs resulted in a $10^{5}$-fold increase in CXCR4 transcript number (Figure 2(a)), a 40\% transfection efficiency, and an over 3fold increase in chemotactic index [135]. In comparison, adenoviral transduction of rat bone marrow-derived MSCs resulted in 95\% CXCR4 expression but only $<2$-fold enhancement in SDF-1-directed cell migration [129]. In another study, rat MSCs that were retrovirally transduced with CXCR4 showed 54\% expression of CXCR4 and an approximately 3 -fold increase in migration towards an SDF-1 gradient compared to non-transduced cells [130]. On the other hand, despite a significant overexpression (93\%) and functionality of CXCR4 in human MSCs, no additional improvement of basal cell migration was observed [132]. CXCR4 transfection of MSCs using IBAfect presents a more efficient approach to improving the therapeutic efficacy of MSCs; however, it needs to be tested in vivo.

Despite the vital role of SDF-1-directed migration, it is limited by the relatively short half-life of SDF-1 and the highly time-dependent nature of the homing of progenitor cells to the site of injury [136]. For example, myocardial SDF-1 expression was increased only during the early postinfarct phase, and as a result only MSCs intravenously infused in temporal vicinity to the early phase of myocardial infarction were recruited to injured myocardium, enhancing angiogenesis and improving cardiac function; further, MSCs injected when the cardiac SDF-1 expression had already fallen did not home to the heart or have a positive effect on the outcome [137]. Attempts to deliver SDF-1, on the other hand, are complicated by rapid diffusion of the chemokine away from the intended site and by enzymatic degradation. SDF1 is degraded by dipeptidyl peptidase IV [138-140] and by MMP-2 and MT1-MMP [141], which are activated at the injured site. These findings raise the need for ways to enhance 
or prime migratory responses to the low physiological levels of SDF-1.

7.2. Priming SDF-1 Homing Responses with Valproic Acid. VPA (also known as 2-propylpentanoic acid) is an anticonvulsant and mood-stabilizing drug approved by the Food and Drug Administration for the treatment of epilepsy and manic disorders. Because in rat MSCs short-term (3 h) VPA treatment more robustly enhanced CXCR4 transcript levels compared to long-term (24 h or longer) treatment [142], we exposed human cord blood-derived MSCs to VPA for 3 or $6 \mathrm{~h}$. We found that increasing doses of VPA up to $10 \mathrm{mM}$ enhanced CXCR4 mRNA expression to levels over 40-fold after $3 \mathrm{~h}$ and about 60 -fold after $6 \mathrm{~h}$ exposure. However, while no upregulation was observed in the surface expression of CXCR4, total CXCR4 protein level was increased. It has been previously shown that CXCR4 is mostly sequestered intracellularly [143] and forms heterodimers with CXCR7 [144]. Therefore it is plausible that an increase in protein expression may not be detectable on the surface of cells. Cord blood-derived MSCs migrated about 2-fold more towards a low SDF-1 gradient $(20 \mathrm{ng} / \mathrm{mL})$ and 4 -fold more towards a high SDF-1 gradient $(100 \mathrm{ng} / \mathrm{mL})$ compared to medium alone. When the cells were pretreated with $5 \mathrm{mM}$ VPA for $3 \mathrm{~h}$ we found that VPA significantly increased transMatrigel chemoinvasion towards a low SDF-1 gradient to a level comparable to the chemoinvasion of untreated cells migrating towards a high SDF-1 gradient (Figure 2(b)). This priming effect of VPA on chemoinvasion towards a low SDF-1 gradient was significantly inhibited by AMD3100, supporting the hypothesis that the increase in chemoinvasion is due to a direct effect of VPA on CXCR4 expression (manuscript submitted).

The ability to cross the endothelium and degrade the extracellular basement membrane matrix is another essential step for MSCs to reach target tissues. Previously we and others showed that MMP-2 is involved in the migration of MSCs $[28,65,145,146]$. We found that VPA increases MMP-2 gene expression and the secretion and activation of pro-MMP2. Consistently, active MMP-2 is secreted at sites of MSC invasion in myocardial tissue [67].

Based on our findings, we proposed that short-term exposure $(3 \mathrm{~h})$ of MSCs to a low dose of VPA $(\leq 5 \mathrm{mM})$ could be used to increase their recruitment to sites of injury. Although our study examined priming of MSC migratory responses in vitro, the ability of VPA to promote MSC homing and to improve functional recovery was also assessed in vivo using a rat model of cerebral ischemia [147]. MSCs primed with VPA $(2.5 \mathrm{mmol} / \mathrm{L}, 3 \mathrm{~h})$ were transplanted into rats $24 \mathrm{~h}$ after transient middle cerebral artery occlusion (MCAO). Priming with VPA increased the number of MSCs homing to the cerebral infarcted regions. MCAO rats receiving VPA-primed MSCs showed markedly improved neurological score, reduced infarct volume, and increased microvessel density in the infarcted penumbra regions. These beneficial effects of VPA priming were reversed by AMD3100 [147]. VPA was shown to enhance MSC migration by upregulation of the histone deacetylase-CXCR4 and glycogen synthase kinase-3 $\beta$-MMP-9 signaling pathways [142]. Because VPA robustly improved the homing efficacy of MSC in vivo, it is likely that fewer MSC would be required to achieve clinical efficacy, thus reducing the risk of cerebral flow interruption and shortening the time necessary to culture MSCs for transplantation.

7.3. Priming with C1q. The initiator of the classical pathway, $\mathrm{Cl}$, consists of $\mathrm{Clq}$ and two other catalytic subunits C1r and $\mathrm{Cls}$. Clq binds to its specific cell-surface receptors (namely, CD93, CR1, gClqR, and $\mathrm{cClqR} /$ calreticulin) to induce a variety of cellular responses [148]. We have previously shown that $\mathrm{Clq}$ enhances the homing-related responses of HSPC through binding to CD93 [149]. In a more recent study we found that $\mathrm{Clq}$ chemoattracts MSCs across reconstituted basement membrane in a dose-dependent manner, and MSCs pretreated with $\mathrm{Clq}$ sense better the SDF-1 gradient [91]. $\mathrm{Clq}$ increases the chemoinvasion of MSCs towards a low concentration of SDF-1 $(20 \mathrm{ng} / \mathrm{mL})$ to a level equivalent to that of a high concentration $(100 \mathrm{ng} / \mathrm{mL})$ by increasing the CXCR4 surface expression from $1.5 \%$ to $9.5 \%$ (Figure $2(\mathrm{c})$ ). Although only a small increase in the percentage of the cells expressing surface CXCR4 was observed, this difference is of biological significance and is enough to elicit a homing response of MSCs consistent with previous studies showing that a slight increase in the percentage of CXCR4-expressing MSCs (e.g., induced by short-term hypoxia) results in significant improvement of migration capacity [150]. Furthermore, we demonstrated that $\mathrm{Clq}$ induces the secretion of MMP-2, which contributes to the migration of MSCs across reconstituted basement membrane.

Similar to the signals induced by C3a and C5a [90], the ERK1/2 signalling pathway was shown to be involved in the migration of MSCs towards Clq as PD98059, a specific ERK inhibitor, significantly inhibited Clq-directed migration of MSCs [91]. Elucidation of the signalling pathways mediating MSC migration is a crucial step towards designing MSCbased therapies. A wide array of signalling pathways has been implicated (reviewed in [151]) and a brief summary follows.

\section{Signalling Pathways in MSC Migration}

Several phosphoinositide 3-kinase $(\mathrm{PI} 3 \mathrm{~K}) /$ protein kinase B (Akt) stimulators including SDF-1 have been shown to increase MSC migration [152]. SDF-1-enhanced MSC migration was mediated through the activation of the PI3K/Akt pathway [26]. Hypoxia conditioning has also been shown to increase MSC migration via the PI3K/Akt pathway, and this effect was abolished by the PI3K inhibitors wortmannin and LY294002 [153]. The levels of phospho-Akt and phosphomitogen-activated protein kinase (MAPK) reached the maximum in the gene-modified CXCR4-MSCs and were restored to the basal level by AMD3100. Treatment of MSCs with PI3K-specific inhibitor (LY294002) and MAPK inhibitor (PD98059) significantly attenuated the migration of the CXCR4-MSCs [98]. It is likely that both PI3K/Akt and MAPK/ERK transduction pathways are involved in the enhancement of MSC migration induced via CXCR4 
overexpression. In fact, MSC migration was inhibited by AMD3100, LY294002, PD98059, and p38MAPK inhibitor (SB203580). Small interfering RNA-mediated knockdown of Akt, ERK, and p38 blocked SDF-1-induced MSC migration [154].

The involvement of a Rho-kinase (ROCK) was also demonstrated using the ROCK inhibitor Y27632 which effectively promoted MSC transendothelial migration; conversely, LY294002 blocked it. Consistently, adenovirus-mediated interference of ROCK in MSCs significantly increased transendothelial migration while overexpression of a PI3K dominant negative mutant in MSCs blocked transendothelial migration [155]. The accumulation of MSCs in the site of myocardial infarct was blocked by LY294002 and phosphorylated Akt was highly increased in SDF-1-treated MSCs [97]. Pharmacological inactivation of AKT2 but not AKT1 significantly decreased cell migration and invasion [156]. Taken together, these results demonstrate the roles of PI3K, Akt, ERK, and p38 signal transduction pathways in SDF-1directed migration of MSCs.

Lastly, Notch signalling was reported to regulate MSC migration and function, at least partially via the modulation of CXCR4 expression. The gene, protein, and cell surface expression of CXCR4 were significantly increased in MSCs when Notch signalling was interrupted by $\gamma$-secretase inhibitor (GSI) or by knockout of the transcription factor RBP-J, the mediator of Notch signalling. The GSI-treated or RBP-J deficient MSCs showed stronger migration toward SDF-1 and toward hepatic ischemia/reperfusion injury than that of control MSCs [157].

\section{Concluding Remarks}

The prevalence of MSC-based clinical therapies calls for rigorous investigations of their efficacy. As with any cellular therapy, national and international health regulatory agencies also typically require thorough validation of toxicology and safety in preclinical animal models, in addition to a demonstration of potency. The use of MSCs in most clinical applications, whether autologous or allogeneic, involves the isolation of cells from various tissues, followed by their ex vivo expansion; however, the lack of standardized cell culture conditions results in heterogeneous populations of cells despite proposed criteria defining characteristics of MSCs and measures of efficacy $[6,158,159]$. In addition, the production of safe MSC products requires compliance with Good Manufacturing Practices to ensure that they are free of any contamination. Recently, the safety of MSCs, particularly in regard to their genetic stability in long-term expansion, cryopreservation, and banking, and the role of serum in cultures, as well as the intravascular delivery of MSCs, was reviewed, and it was concluded that the vast majority of clinical trials conducted with MSCs have not reported major health concerns [160, 161]. Malignant transformation of infused MSCs has been refuted as these cells did not demonstrate sustained engraftment [162]. Strategies to effectively direct MSCs to sites of injury and inflammation including genetic manipulation, modifying expression of homing and adhesion receptors, and antibody or peptidedirected cell targeting [110] are actively being pursued. It is likewise essential to ensure that these manipulations of MSCs do not alter their overall genotype, phenotype, functional potential, and other biological characteristics. For example, a possible cause of the failure of MSC-based immunotherapy in clinical trials has been attributed to impairment of immunosuppressive properties of cryopreserved MSCs [23, 163]. An understanding of the mechanisms of MSC migration, as part of the scientific assessment of the pharmacology of MSCbased therapies, is of paramount importance. Modulation of the homing properties of MSCs could allow for their efficient recruitment to sites of injury and inflammation and could reduce the dose of infused cells required, potentially limiting the cost of this therapy as well as the risks of transformation during culture expansion.

\section{Conflict of Interests}

The authors declare that there is no conflict of interests regarding the publication of this paper.

\section{Acknowledgments}

This work was supported by Canadian Blood Services (CBS)/Canadian Institutes of Health Research Blood Utilization \& Conservation Initiative grant and a CBS Intramural grant awarded to Anna Janowska-Wieczorek.

\section{References}

[1] A. J. Friedenstein, U. F. Gorskaja, and N. N. Kulagina, "Fibroblast precursors in normal and irradiated mouse hematopoietic organs," Experimental Hematology, vol. 4, no. 5, pp. 267-274, 1976.

[2] F. Rastegar, D. Shenaq, J. Huang et al., "Mesenchymal stem cells: molecular characteristics and clinical applications," World Journal of Stem Cells, vol. 2, no. 4, pp. 67-80, 2010.

[3] A. F. Steinert, L. Rackwitz, F. Gilbert, U. Noth, and R. S. Tuan, "Concise review: the clinical application of mesenchymal stem cells for musculoskeletal regeneration: current status and perspectives," Stem Cells Translational Medicine, vol. 1, no. 3, pp. 237-247, 2012.

[4] W. R. Otto and N. A. Wright, "Mesenchymal stem cells: from experiment to clinic," Fibrogenesis and Tissue Repair, vol. 4, no. 1, article 20, 2011.

[5] R. Hass, C. Kasper, S. Bohm, and R. Jacobs, "Different populations and sources of human mesenchymal stem cells (MSC): a comparison of adult and neonatal tissue-derived MSC," Cell Communication and Signaling, vol. 9, article 12, 2011.

[6] M. Dominici, K. Le Blanc, I. Mueller et al., "Minimal criteria for defining multipotent mesenchymal stromal cells. The international society for cellular therapy position statement," Cytotherapy, vol. 8, no. 4, pp. 315-317, 2006.

[7] J. Kim, J. M. Shin, Y. J. Jeon, H. M. Chung, and J.-I. Chae, "Proteomic validation of multifunctional molecules in mesenchymal stem cells derived from human bone marrow, umbilical cord blood and peripheral blood," PLoS One, vol. 7, no. 5, Article ID e32350, 2012. 
[8] L. Hu, J. Hu, J. Zhao et al., "Side-by-side comparison of the biological characteristics of human umbilical cord and adipose tissue-derived mesenchymal stem cells," BioMed Research International, vol. 2013, Article ID 438243, 12 pages, 2013.

[9] V. Neirinckx, V. Neirinckx, C. Coste, B. Rogister, and S. WisletGendebien, "Concise review: adult mesenchymal stem cells, adult neural crest stem cells, and therapy of neurological pathologies: a state of play," Stem Cells Translational Medicine, vol. 2, no. 4, pp. 284-296, 2013.

[10] X. B. Wu and R. Tao, "Hepatocyte differentiation of mesenchymal stem cells," Hepatobiliary \& Pancreatic Diseases International, vol. 11, no. 4, pp. 360-371, 2012.

[11] P. Bianco, R. Barker, O. Brüstle et al., "Regulation of stem cell therapies under attack in Europe: for whom the bell tolls," The EMBO Journal, vol. 32, no. 11, pp. 1489-1495, 2013.

[12] P. Bianco, X. Cao, P. S. Frenette et al., "The meaning, the sense and the significance: translating the science of mesenchymal stem cells into medicine," Nature Medicine, vol. 19, no. 1, pp. 3542, 2013.

[13] L. da Silva Meirelles, A. M. Fontes, D. T. Covas, and A. I. Caplan, "Mechanisms involved in the therapeutic properties of mesenchymal stem cells," Cytokine and Growth Factor Reviews, vol. 20, no. 5-6, pp. 419-427, 2009.

[14] R. A. Boomsma and D. L. Geenen, "Mesenchymal stem cells secrete multiple cytokines that promote angiogenesis and have contrasting effects on chemotaxis and apoptosis," PLoS One, vol. 7, no. 4, Article ID e35685, 2012.

[15] J. Doorn, G. Moll, K. Le Blanc, C. van Blitterswijk, and J. De Boer, "Therapeutic applications of mesenchymal stromal cells: paracrine effects and potential improvements," Tissue Engineering $B$, vol. 18, no. 2, pp. 101-115, 2012.

[16] S. H. Ranganath, O. Levy, M. S. Inamdar, and J. M. Karp, "Harnessing the mesenchymal stem cell secretome for the treatment of cardiovascular disease," Cell Stem Cell, vol. 10, no. 3, pp. 244-258, 2012.

[17] K. English, "Mechanisms of mesenchymal stromal cell immunomodulation," Immunology and Cell Biology, vol. 19, no. 1, pp. 9119-9126, 2013.

[18] J. R. Lavoie and M. Rosu-Myles, "Uncovering the secretes of mesenchymal stem cells," Biochimie, vol. 95 , no. 12, pp. 22122221, 2013.

[19] R. H. Lee, A. A. Pulin, M. J. Seo et al., "Intravenous hMSCs improve myocardial infarction in mice because cells embolized in lung are activated to secrete the anti-inflammatory protein TSG-6," Cell Stem Cell, vol. 5, no. 1, pp. 54-63, 2009.

[20] L. Shin and D. A. Peterson, "Human mesenchymal stem cell grafts enhance normal and impaired wound healing by recruiting existing endogenous tissue stem/progenitor cells," Stem Cells Translational Medicine, vol. 2, no. 1, pp. 33-42, 2013.

[21] F.-M. Chen, L.-A. Wu, M. Zhang, R. Zhang, and H.-H. Sun, "Homing of endogenous stem/progenitor cells for in situ tissue regeneration: promises, strategies, and translational perspectives," Biomaterials, vol. 32, no. 12, pp. 3189-3209, 2011.

[22] T. Yi and S. U. Song, "Immunomodulatory properties of mesenchymal stem cells and their therapeutic applications," Archives of Pharmacal Research, vol. 35, no. 2, pp. 213-221, 2012.

[23] J. Galipeau, “The mesenchymal stromal cells dilemma-does a negative phase III trial of random donor mesenchymal stromal cells in steroid-resistant graft-versus-host disease represent a death knell or a bump in the road?" Cytotherapy, vol. 15, no. 1 , pp. 2-8, 2013.
[24] C. Cencioni, M. C. Capogrossi, and M. Napolitano, "The SDF1/CXCR4 axis in stem cell preconditioning," Cardiovascular Research, vol. 94, no. 3, pp. 400-407, 2012.

[25] Y. Wu and R. C. H. Zhao, "The role of chemokines in mesenchymal stem cell homing to myocardium," Stem Cell Reviews and Reports, vol. 8, no. 1, pp. 243-250, 2012.

[26] X. Liu, B. Duan, Z. Cheng et al., "SDF-1/CXCR4 axis modulates bone marrow mesenchymal stem cell apoptosis, migration and cytokine secretion," Protein and Cell, vol. 2, no. 10, pp. 845-854, 2011.

[27] I. Petit, D. Jin, and S. Rafii, "The SDF-1-CXCR4 signaling pathway: a molecular hub modulating neo-angiogenesis," Trends in Immunology, vol. 28, no. 7, pp. 299-307, 2007.

[28] B.-R. Son, L. A. Marquez-Curtis, M. Kucia et al., "Migration of bone marrow and cord blood mesenchymal stem cells in vitro is regulated by stromal-derived factor-1-CXCR4 and hepatocyte growth factor-c-met axes and involves matrix metalloproteinases," Stem Cells, vol. 24, no. 5, pp. 1254-1264, 2006.

[29] M. Honczarenko, Y. Le, M. Swierkowski, I. Ghiran, A. M. Glodek, and L. E. Silberstein, "Human bone marrow stromal cells express a distinct set of biologically functional chemokine receptors," Stem Cells, vol. 24, no. 4, pp. 1030-1041, 2006.

[30] G. Ren, X. Chen, F. Dong et al., "Concise review: mesenchymal stem cells and translational medicine: emerging issues," Stem Cells Translational Medicine, vol. 1, no. 1, pp. 51-58, 2012.

[31] P. S. Frenette, S. Pinho, D. Lucas, and C. Scheiermann, "Mesenchymal stem cell: keystone of the hematopoietic stem cell niche and a stepping-stone for regenerative medicine," Annual Review of Immunology, vol. 31, pp. 285-316, 2013.

[32] D. J. Prockop and J. Youn Oh, "Mesenchymal stem/stromal cells (MSCs): role as guardians of inflammation," Molecular Therapy, vol. 20, no. 1, pp. 14-20, 2012.

[33] K. S. Kang, I. S. Shin, M. S. Ko, J. Y. Jo, and J. C. Ra, "Journey of mesenchymal stem cells for homing: strategies to enhance efficacy and safety of stem cell therapy," Stem Cells International, vol. 2012, Article ID 342968, 11 pages, 2012.

[34] A. Augello, T. B. Kurth, and C. de Bari, "Mesenchymal stem cells: a perspective from in vitro cultures to in vivo migration and niches," European Cells and Materials, vol. 20, pp. 121-133, 2010.

[35] S. Méndez-Ferrer, T. V. Michurina, F. Ferraro et al., "Mesenchymal and haematopoietic stem cells form a unique bone marrow niche," Nature, vol. 466, no. 7308, pp. 829-834, 2010.

[36] W. S. Vanden Berg-Foels, "In situ tissue regeneration: chemoattractants for endogenous stem cell recruitment," Tissue Engineering B, 2013.

[37] A. Stolzing, E. Jones, D. McGonagle, and A. Scutt, "Age-related changes in human bone marrow-derived mesenchymal stem cells: consequences for cell therapies," Mechanisms of Ageing and Development, vol. 129, no. 3, pp. 163-173, 2008.

[38] G. C. Gurtner, S. Werner, Y. Barrandon, and M. T. Longaker, "Wound repair and regeneration," Nature, vol. 453, no. 7193, pp. 314-321, 2008.

[39] L. Orozco, A. Munar, R. Soler et al., "Treatment of knee osteoarthritis with autologous mesenchymal stem cells: a pilot study," Transplantation, vol. 95, no. 12, pp. 1535-1541, 2013.

[40] M. Haack-Sorensen, T. Friis, A. B. Mathiasen et al., "Direct intramyocardial mesenchymal stromal cell injections in patients with severe refractory angina: one-year follow-up," Cell Transplantation, vol. 22, no. 3, pp. 521-528, 2013. 
[41] K. Kollar, M. M. Cook, K. Atkinson, and G. Brooke, "Molecular mechanisms involved in mesenchymal stem cell migration to the site of acute myocardial infarction," International Journal of Cell Biology, vol. 2009, Article ID 904682, 8 pages, 2009.

[42] M. E. Bernardo and W. E. Fibbe, "Safety and efficacy of mesenchymal stromal cell therapy in autoimmune disorders," Annals of the New York Academy of Sciences, vol. 1266, pp. 107117, 2012.

[43] L. von Bahr, B. Sundberg, L. Lönnies et al., "Long-term complications, immunologic effects, and role of passage for outcome in mesenchymal stromal cell therapy," Biology of Blood and Marrow Transplantation, vol. 18, no. 4, pp. 557-564, 2012.

[44] A. Keating, "Mesenchymal stromal cells: new directions," Cell Stem Cell, vol. 10, no. 6, pp. 709-716, 2012.

[45] M. E. Bernardo and W. E. Fibbe, "Mesenchymal stromal cells: sensors and switchers of inflammation," Cell Stem Cell, vol. 13, no. 4, pp. 392-402, 2013.

[46] G. P. Zheng, M. H. Ge, Q. Shu, M. Rojas, and J. Xu, "Mesenchymal stem cells in the treatment of pediatric diseases," World Journal of Pediatrics, vol. 9, no. 3, pp. 197-211, 2013.

[47] E. Eggenhofer, V. Benseler, A. Kroemer et al., "Mesenchymal stem cells are short-lived and do not migrate beyond the lungs after intravenous infusion," Frontiers in Immunology, vol. 3, article 297, 2012.

[48] C. Toma, W. R. Wagner, S. Bowry, A. Schwartz, and F. Villanueva, "Fate of culture-expanded mesenchymal stem cells in the microvasculature: in vivo observations of cell kinetics," Circulation Research, vol. 104, no. 3, pp. 398-402, 2009.

[49] Y. Guo, L. Su, J. Wu et al., "Assessment of the green florescence protein labeling method for tracking implanted mesenchymal stem cells," Cytotechnology, vol. 64, no. 4, pp. 391-401, 2012.

[50] J. A. Wood, D. J. Chung, and S. A. Park, "Periocular and intraarticular injection of canine adipose-derived mesenchymal stem cells: an in vivo imaging and migration study, Journal of Ocular Pharmacology and Therapeutics, vol. 28, no. 3, pp. 307317, 2012.

[51] K. Cheng, P. Rai, A. Plagov et al., "Transplantation of bone marrow-derived MSCs improves cisplatinum-induced renal injury through paracrine mechanisms," Experimental and Molecular Pathology, vol. 94, no. 3, pp. 466-473, 2013.

[52] C. Hu, X. Yong, C. Li et al., "CXCL12/CXCR4 axis promotes mesenchymal stem cell mobilization to burn wounds and contributes to wound repair," The Journal of Surgical Research, vol. 183, no. 1, pp. 427-434, 2013.

[53] E. M. Horwitz, P. L. Gordon, W. K. K. Koo et al., "Isolated allogeneic bone marrow-derived mesenchymal cells engraft and stimulate growth in children with osteogenesis imperfecta: implications for cell therapy of bone," Proceedings of the National Academy of Sciences of the United States of America, vol. 99, no. 13, pp. 8932-8937, 2002.

[54] N. Nagaya, T. Fujii, T. Iwase et al., "Intravenous administration of mesenchymal stem cells improves cardiac function in rats with acute myocardial infarction through angiogenesis and myogenesis," American Journal of Physiology: Heart and Circulatory Physiology, vol. 287, no. 6, pp. H2670-H2676, 2004.

[55] M. A. González, E. González-Rey, L. Rico, D. Büscher, and M. Delgado, "Treatment of experimental arthritis by inducing immune tolerance with human adipose-derived mesenchymal stem cells," Arthritis and Rheumatism, vol. 60, no. 4, pp. 10061019, 2009.

[56] H. Kanazawa, Y. Fujimoto, T. Teratani et al., "Bone marrowderived mesenchymal stem cells ameliorate hepatic ischemia reperfusion injury in a rat model," PLoS ONE, vol. 6, no. 4, Article ID e19195, 2011.

[57] J. M. Karp and G. S. Leng Teo, "Mesenchymal stem cell homing: the devil is in the details," Cell Stem Cell, vol. 4, no. 3, pp. 206216, 2009.

[58] M. J. Crop, C. C. Baan, S. S. Korevaar et al., "Inflammatory conditions affect gene expression and function of human adipose tissue-derived mesenchymal stem cells," Clinical and Experimental Immunology, vol. 162, no. 3, pp. 474-486, 2010.

[59] A. C. M. Assis, J. L. Carvalho, B. A. Jacoby et al., "Timedependent migration of systemically delivered bone marrow mesenchymal stem cells to the infarcted heart," Cell Transplantation, vol. 19, no. 2, pp. 219-230, 2010.

[60] S. Jung, K. M. Panchalingam, L. Rosenberg, and L. A. Behie, "Ex vivo expansion of human mesenchymal stem cells in defined serum-free media," Stem Cells International:, vol. 2012, Article ID 123030, 21 pages, 2012.

[61] M. W. Lee, D. S. Kim, S. Ryu et al., "Effect of ex vivo culture conditions on immunosuppression by human mesenchymal stem cells," BioMed Research International, vol. 2013, Article ID 154919, 10 pages, 2013.

[62] W. J. C. Rombouts and R. E. Ploemacher, "Primary murine MSC show highly efficient homing to the bone marrow but lose homing ability following culture," Leukemia, vol. 17, no. 1, pp. 160-170, 2003.

[63] S. Morikawa, Y. Mabuchi, Y. Kubota et al., "Prospective identification, isolation, and systemic transplantation of multipotent mesenchymal stem cells in murine bone marrow," Journal of Experimental Medicine, vol. 206, no. 11, pp. 2483-2496, 2009.

[64] Q. Li, X. Zhou, Y. Shi et al., "In vivo tracking and comparison of the therapeutic effects of MSCs and HSCs for liver injury," PLoS One, vol. 8, no. 4, Article ID e62363, 2013.

[65] C. Song and G. Li, "CXCR4 and matrix metalloproteinase-2 are involved in mesenchymal stromal cell homing and engraftment to tumors," Cytotherapy, vol. 13, no. 5, pp. 549-561, 2011.

[66] L. Liu, M. A. Eckert, H. Riazifar, D.-K. Kang, D. Agalliu, and W. Zhao, "From blood to the brain: can systemically transplanted mesenchymal stem cells cross the blood-brain barrier?" Stem Cells International, vol. 2013, Article ID 435093, 7 pages, 2013.

[67] C. Steingen, F. Brenig, L. Baumgartner, J. Schmidt, A. Schmidt, and W. Bloch, "Characterization of key mechanisms in transmigration and invasion of mesenchymal stem cells," Journal of Molecular and Cellular Cardiology, vol. 44, no. 6, pp. 1072-1084, 2008.

[68] H. Yagi, A. Soto-Gutierrez, B. Parekkadan et al., "Mesenchymal stem cells: mechanisms of immunomodulation and homing," Cell Transplantation, vol. 19, no. 6-7, pp. 667-679, 2010.

[69] G. Chamberlain, H. Smith, G. E. Rainger, and J. Middleton, "Mesenchymal stem cells exhibit firm adhesion, crawling, spreading and transmigration across aortic endothelial cells: effects of chemokines and shear," PLoS ONE, vol. 6, no. 9, Article ID e25663, 2011.

[70] Y. Wang, Y. Deng, and G.-Q. Zhou, "SDF-1 $\alpha / C X C R 4-m e d i a t e d$ migration of systemically transplanted bone marrow stromal cells towards ischemic brain lesion in a rat model," Brain Research, vol. 1195, pp. 104-112, 2008.

[71] F. Dong, J. Harvey, A. Finan, K. Weber, U. Agarwal, and M. S. Penn, "Myocardial CXCR4 expression is required for mesenchymal stem cell mediated repair following acute myocardial infarction," Circulation, vol. 126, no. 3, pp. 314-324, 2012. 
[72] C. M. Rice and N. J. Scolding, "Adult human mesenchymal cells proliferate and migrate in response to chemokines expressed in demyelination," Cell Adhesion and Migration, vol. 4, no. 2, pp. 235-240, 2010.

[73] K. M. Akram, S. Samad, M. A. Spiteri, and N. R. Forsyth, "Mesenchymal stem cells promote alveolar epithelial cell wound repair in vitro through distinct migratory and paracrine mechanisms," Respiratory Research, vol. 14, article 9, 2013.

[74] N. C. Joyce, D. L. Harris, V. Markov, Z. Zhang, and B. Saitta, "Potential of human umbilical cord blood mesenchymal stem cells to heal damaged corneal endothelium," Molecular Vision, vol. 18, pp. 547-564, 2012.

[75] R. Manuguerra-Gagne, P. R. Boulos, A. Ammar et al., "Transplantation of mesenchymal stem cells promotes tissue regeneration in a glaucoma model through laser-induced paracrine factor secretion and progenitor cell recruitment," Stem Cells, vol. 31, no. 6, pp. 1136-1148, 2013.

[76] A. F. Wise and S. D. Ricardo, "Mesenchymal stem cells in kidney inflammation and repair," Nephrology, vol. 17, no. 1, pp. 1-10, 2012.

[77] J. Stagg and J. Galipeau, "Mechanisms of immune modulation by mesenchymal stromal cells and clinical translation," Current Molecular Medicine, vol. 13, no. 5, pp. 856-867, 2013.

[78] H. Smith, C. Whittall, B. Weksler, and J. Middleton, "Chemokines stimulate bidirectional migration of human mesenchymal stem cells across bone marrow endothelial cells," Stem Cells and Development, vol. 21, no. 3, pp. 476-486, 2012.

[79] V. Alexeev, A. Donahue, J. Uitto, and O. Igoucheva, "Analysis of chemotactic molecules in bone marrow-derived mesenchymal stem cells and the skin: Ccl27-Ccr10 axis as a basis for targeting to cutaneous tissues," Cytotherapy, vol. 15, no. 2, pp. 171.e1184.el, 2013.

[80] M. W. Lee, D. S. Kim, K. H. Yoo et al., "Human bone marrowderived mesenchymal stem cell gene expression patterns vary with culture conditions," Blood Research, vol. 48, no. 2, pp. 107114, 2013.

[81] F. Belema-Bedada, S. Uchida, A. Martire, S. Kostin, and T. Braun, "Efficient homing of multipotent adult mesenchymal stem cells depends on FROUNT-mediated Clustering of CCR2," Cell Stem Cell, vol. 2, no. 6, pp. 566-575, 2008.

[82] D.-S. Kim, J. H. Kim, J. Kwon Lee et al., "Overexpression of CXC chemokine receptors is required for the superior gliomatracking property of umbilical cord blood-derived mesenchymal stem cells," Stem Cells and Development, vol. 18, no. 3, pp. 511-519, 2009.

[83] V. Sordi, M. L. Malosio, F. Marchesi et al., "Bone marrow mesenchymal stem cells express a restricted set of functionally active chemokine receptors capable of promoting migration to pancreatic islets," Blood, vol. 106, no. 2, pp. 419-427, 2005.

[84] J. Huang, Z. Zhang, J. Guo et al., "Genetic modification of mesenchymal stem cells overexpressing ccrl increases cell viability, migration, engraftment, and capillary density in the injured myocardium," Circulation Research, vol. 106, no. 11, pp. 1753-1762, 2010.

[85] S. Vogel, C. Peters, N. Etminan et al., "Migration of mesenchymal stem cells towards glioblastoma cells depends on hepatocyte-growth factor and is enhanced by aminolaevulinic acid-mediated photodynamic treatment," Biochemical and Biophysical Research Communications, vol. 431, no. 3, pp. 428-432, 2013.

[86] J. van de Kamp, W. Jahnen-Dechent, B. Rath, R. Knuechel, and S. Neuss, "Hepatocyte growth factor-loaded biomaterials for mesenchymal stem cell recruitment," Stem Cells International, vol. 2013, Article ID 892065, 9 pages, 2013.

[87] M. B. Herrera, B. Bussolati, S. Bruno et al., "Exogenous mesenchymal stem cells localize to the kidney by means of CD44 following acute tubular injury," Kidney International, vol. 72, no. 4, pp. 430-441, 2007.

[88] C. Kim, G. Schneider, A. Abdel-Latif et al., "Ceramide-1phosphate regulates migration of multipotent stromal cells and endothelial progenitor cells-implications for tissue regeneration," Stem Cells, vol. 31, no. 3, pp. 500-510, 2013.

[89] P. Gasque, "Complement: a unique innate immune sensor for danger signals," Molecular Immunology, vol. 41, no. 11, pp. 10891098, 2004.

[90] I. U. Schraufstatter, R. G. DiScipio, M. Zhao, and S. K. Khaldoyanidi, "C3a and $\mathrm{C} 5 \mathrm{a}$ are chemotactic factors for human mesenchymal stem cells, which cause prolonged ERK1/2 phosphorylation," Journal of Immunology, vol. 182, no. 6, pp. 38273836, 2009.

[91] Y. Qiu, L. A. Marquez-Curtis, and A. Janowska-Wieczorek, "Mesenchymal stromal cells derived from umbilical cord blood migrate in response to complement Clq," Cytotherapy, vol. 14, no. 3, pp. 285-295, 2012.

[92] S. R. Baglio, D. M. Pegtel, and N. Baldini, "Mesenchymal stem cell secreted vesicles provide novel opportunities in (stem) cellfree therapy," Frontiers in Physiology, vol. 3, article 359, 2012.

[93] M. Z. Ratajczak, M. Kucia, T. Jadczyk et al., "Pivotal role of paracrine effects in stem cell therapies in regenerative medicine-can we translate stem cell-secreted paracrine factors and microvesicles into better therapeutic strategies?" Leukemia, vol. 26, no. 6, pp. 1166-1173, 2012.

[94] H.-S. Kim, D.-Y. Choi, S. J. Yun et al., "Proteomic analysis of microvesicles derived from human mesenchymal stem cells," Journal of Proteome Research, vol. 11, no. 2, pp. 839-849, 2012.

[95] S. K. Ghadge, S. Mühlstedt, C. Özcelik, and M. Bader, "SDF$1 \alpha$ as a therapeutic stem cell homing factor in myocardial infarction," Pharmacology and Therapeutics, vol. 129, no. 1, pp. 97-108, 2011.

[96] M. S. Penn, J. Pastore, T. Miller, and R. Aras, "SDF-1 in myocardial repair," Gene Therapy, vol. 19, no. 6, pp. 583-587, 2012.

[97] J. Yu, M. Li, Z. Qu, D. Yan, D. Li, and Q. Ruan, "SDF-1/CXCR4mediated migration of transplanted bone marrow stromal cells toward areas of heart myocardial infarction through activation of PI3K/Akt," Journal of Cardiovascular Pharmacology, vol. 55, no. 5, pp. 496-505, 2010.

[98] N. Liu, J. Tian, J. Cheng, and J. Zhang, “Directional migration of CXCR4 gene-modified bone marrow-derived mesenchymal stem cells to the kidney area after acute kidney injury," Journal of Cellular Biochemistry, vol. 114, no. 12, pp. 2677-2268.

[99] S. Stich, M. Haag, T. Häupl et al., "Gene expression profiling of human mesenchymal stem cells chemotactically induced with CXCL12," Cell and Tissue Research, vol. 336, no. 2, pp. 225-236, 2009.

[100] T. Kitaori, H. Ito, E. M. Schwarz et al., "Stromal cell-derived factor 1/CXCR4 signaling is critical for the recruitment of mesenchymal stem cells to the fracture site during skeletal repair in a mouse model," Arthritis and Rheumatism, vol. 60, no. 3, pp. 813-823, 2009.

[101] J. M. Burns, B. C. Summers, Y. Wang et al., "A novel chemokine receptor for SDF-1 and I-TAC involved in cell survival, cell adhesion, and tumor development," Journal of Experimental Medicine, vol. 203, no. 9, pp. 2201-2213, 2006. 
[102] H. Liu, S. Liu, Y. Li et al., "The role of SDF-1-CXCR4/CXCR7 axis in the therapeutic effects of hypoxia-preconditioned mesenchymal stem cells for renal ischemia/reperfusion injury," PLoS One, vol. 7, no. 4, Article ID e34608, 2012.

[103] B. A. Zabel, Y. Wang, S. Lewén et al., "Elucidation of CXCR7mediated signaling events and inhibition of CXCR4-mediated tumor cell transendothelial migration by CXCR7 ligands," Journal of Immunology, vol. 183, no. 5, pp. 3204-3211, 2009.

[104] N. Liu, A. Patzak, and J. Zhang, "CXCR4-overexpressing bone marrow-derived mesenchymal stem cells improve repair of acute kidney injury," American Journal of Physiology: Renal Physiology, vol. 305, no. 7, pp. F1064-F1073, 2013.

[105] Y. Gheisari, K. Azadmanesh, N. Ahmadbeigi et al., "Genetic modification of mesenchymal stem cells to overexpress CXCR4 and CXCR7 does not improve the homing and therapeutic potentials of these cells in experimental acute kidney injury," Stem Cells and Development, vol. 21, no. 16, pp. 2969-2980, 2012.

[106] J. Cao, L. Wang, Z.-J. Du et al., "Recruitment of exogenous mesenchymal stem cells in mandibular distraction osteogenesis by the stromal cell-derived factor-1/chemokine receptor- 4 pathway in rats," British Journal of Oral and Maxillofacial Surgery, 2013.

[107] X. Yu, D. Chen, Y. Zhang et al., "Overexpression of CXCR4 in mesenchymal stem cells promotes migration, neuroprotection and angiogenesis in a rat model of stroke," Journal of the Neurological Sciences, vol. 316, no. 1-2, pp. 141-149, 2012.

[108] R. F. Wynn, C. A. Hart, C. Corradi-Perini et al., "A small proportion of mesenchymal stem cells strongly expresses functionally active CXCR4 receptor capable of promoting migration to bone marrow," Blood, vol. 104, no. 9, pp. 2643-2645, 2004.

[109] M. W. Maijenburg, C. E. van der Schoot, and C. Voermans, "Mesenchymal stromal cell migration: possibilities to improve cellular therapy," Stem Cells and Development, vol. 21, no. 1, pp. 19-29, 2012.

[110] J. Thomas Kean, Paul Lin, I. Arnold Caplan, and E. James Dennis, "MSCs: delivery routes and engraftment, cell-targeting strategies, and immune modulation," Stem Cells International, vol. 2013, Article ID 732742, 13 pages, 2013.

[111] D. Sarkar, J. A. Spencer, J. A. Phillips et al., "Engineered cell homing," Blood, vol. 118, no. 25, pp. e184-e191, 2011.

[112] I. K. Ko, B.-G. Kim, A. Awadallah et al., "Targeting improves MSC treatment of inflammatory bowel disease," Molecular Therapy, vol. 18, no. 7, pp. 1365-1372, 2010.

[113] O. Levy, W. Zhao, L. J. Mortensen et al., "mRNA-engineered mesenchymal stem cells for targeted delivery of interleukin-10 to sites of inflammation," Blood, vol. 122, no. 14, pp. e23-e32, 2013.

[114] W. Yao, M. Guan, J. Jia et al., "Reversing Bone Loss by Directing Mesenchymal Stem Cells to the Bone," Stem Cells, vol. 31, no. 9, pp. 2003-2014, 2013.

[115] C. Xinaris, M. Morigi, V. Benedetti et al., "A novel strategy to enhance mesenchymal stem cell migration capacity and promote tissue repair in an injury specific fashion," Cell Transplantion, vol. 22, no. 3, pp. 423-436, 2013.

[116] J.-Y. Hahn, H.-J. Cho, H.-J. Kang et al., "Pre-treatment of mesenchymal stem cells with a combination of growth factors enhances gap junction formation, cytoprotective effect on cardiomyocytes, and therapeutic efficacy for myocardial infarction," Journal of the American College of Cardiology, vol. 51, no. 9, pp. 933-943, 2008.

[117] G. N. Jones, D. Moschidou, K. Lay et al., "pregulating CXCR4 in human fetal mesenchymal stem cells enhances engraftment and bone mechanics in a mouse model of osteogenesis imperfecta," Stem Cells Translational Medicine, vol. 1, no. 1, pp. 70-78, 2012.

[118] Y. S. Kim, M. Y. Noh, J. Y. Kim et al., "Direct GSK-3beta inhibition enhances mesenchymal stromal cell migration by increasing expression of beta-PIX and CXCR4," Molecular Neurobiology, vol. 47, no. 2, pp. 811-820, 2013.

[119] Q. Yu, L. Chen, Y. You et al., "Erythropoietin combined with granulocyte colony-stimulating factor enhances MMP-2 expression in mesenchymal stem cells and promotes cell migration," Molecular Medicine Reports, vol. 4, no. 1, pp. 31-36, 2011.

[120] N. Noiseux, M. Borie, A. Desnoyers et al., "Preconditioning of stem cells by oxytocin to improve their therapeutic potential," Endocrinology, vol. 153, no. 11, pp. 5361-5372, 2012.

[121] J. Xie, H. Wang, T. Song et al., “Tanshinone IIA and astragaloside IV promote the migration of mesenchymal stem cells by up-regulation of CXCR4," Protoplasma, vol. 250, no. 2, pp. 521530, 2013.

[122] H. Gul, L. A. Marquez-Curtis, N. Jahroudi, J. Lo, A. R. Turner, and A. Janowska-Wieczorek, "Valproic acid increases CXCR4 expression in hematopoietic stem/progenitor cells by chromatin remodeling," Stem Cells and Development, vol. 18, no. 6, pp. 831838, 2009.

[123] L. Liu, Q. Yu, J. Lin et al., "Hypoxia-inducible factor-1 $\alpha$ is essential for hypoxia-induced mesenchymal stem cell mobilization into the peripheral blood," Stem cells and development, vol. 20, no. 11, pp. 1961-1971, 2011.

[124] G. Vertelov, L. Kharazi, M. G. Muralidhar, G. Sanati, T. Tankovich, and A. Kharazi, "High targeted migration of human mesenchymal stem cells grown in hypoxia is associated with enhanced activation of RhoA," Stem Cell Research \& Therapy, vol. 4, no. 1: article 5, 2013.

[125] Z. Zhao, C. Watt, A. Karystinou et al., "Directed migration of human bone marrow mesenchymal stem cells in a physiological direct current electric field," European Cells \& Materials, vol. 22, pp. 344-358, 2011.

[126] S. R. Burks, A. Ziadloo, S. J. Kim, B. A. Nguyen, and J. A. Frank, "Noninvasive pulsed focused ultrasound allows spatiotemporal control of targeted homing for multiple stem cell types in murine skeletal muscle and the magnitude of cell homing can be increased through repeated applications," Stem Cells, vol. 31, no. 11, pp. 2551-2560, 2013.

[127] L. Yuan, N. Sakamoto, G. Song, and M. Sato, "Low-level shear stress induces human mesenchymal stem cell migration through the SDF-1/CXCR4 axis via MAPK signaling pathways," Stem Cells and Development, vol. 22, no. 17, pp. 2384-2393, 2013.

[128] S. B. Zhou, J. Wang, C. A. Chiang, L. L. Sheng, and Q. F. Li, "Mechanical stretch upregulates Sdf-lalpha in skin tissue and induces migration of circulating bone marrow-derived stem cells into the expanded skin," Stem Cells, 2013.

[129] D. Zhang, G.-C. Fan, X. Zhou et al., "Over-expression of CXCR4 on mesenchymal stem cells augments myoangiogenesis in the infarcted myocardium," Journal of Molecular and Cellular Cardiology, vol. 44, no. 2, pp. 281-292, 2008.

[130] Z. Cheng, L. Ou, X. Zhou et al., “Targeted migration of mesenchymal stem cells modified with CXCR4 gene to infarcted myocardium improves cardiac performance," Molecular Ther$a p y$, vol. 16, no. 3, pp. 571-579, 2008.

[131] S. Bobis-Wozowicz, K. Miekus, E. Wybieralska et al., "Genetically modified adipose tissue-derived mesenchymal stem cells overexpressing CXCR4 display increased motility, invasiveness, and homing to bone marrow of NOD/SCID mice," Experimental Hematology, vol. 39, no. 6, pp. 686-e4, 2011. 
[132] J. M. Wiehe, Z. Kaya, J. M. Homann et al., "GMP-adapted overexpression of CXCR4 in human mesenchymal stem cells for cardiac repair," International Journal of Cardiology, vol. 167, no. 5, pp. 2073-2081, 2012.

[133] C. L. Da Silva, C. Madeira, R. D. Mendes et al., "Nonviral gene delivery to mesenchymal stem cells using cationic liposomes for gene and cell therapy," Journal of Biomedicine and Biotechnology, vol. 2010, Article ID 735349, 12 pages, 2010.

[134] H. Gul-Uludag, P. Xu, L. A. Marquez-Curtis, J. Xing, A. Janowska-Wieczorek, and J. Chen, "Cationic liposome-mediated CXCR4 gene delivery into hematopoietic stem/progenitor cells: implications for clinical transplantation and gene therapy," Stem Cells and Development, vol. 2, no. 10, pp. 1587-1596, 2012.

[135] L. A. Marquez-Curtis, H. Gul-Uludag, P. Xu, J. Chen, and A. Janowska-Wieczorek, "CXCR4 transfection of cord blood mesenchymal stromal cells with the use of cationic liposome enhances their migration toward stromal cell-derived factor-1," Cytotherapy, vol. 15, no. 7, pp. 840-849, 2013.

[136] J. W. Murphy, Y. Cho, A. Sachpatzidis, C. Fan, M. E. Hodsdon, and E. Lolis, "Structural and functional basis of CXCL12 (stromal cell-derived factor- $1 \alpha$ ) binding to heparin," The Journal of Biological Chemistry, vol. 282, no. 13, pp. 10018-10027, 2007.

[137] J. Ma, J. Ge, S. Zhang et al., "Time course of myocardial stromal cell-derived factor 1 expression and beneficial effects of intravenously administered bone marrow stem cells in rats with experimental myocardial infarction," Basic Research in Cardiology, vol. 100, no. 3, pp. 217-223, 2005.

[138] V. F. M. Segers, T. Tokunou, L. J. Higgins, C. MacGillivray, J. Gannon, and R. T. Lee, "Local delivery of protease-resistant stromal cell derived factor-1 for stem cell recruitment after myocardial infarction," Circulation, vol. 116, no. 15, pp. 16831692, 2007.

[139] K. W. Christopherson II, G. Hangoc, and H. E. Broxmeyer, "Cell surface peptidase CD26/dipeptidylpeptidase IV regulates CXCL12/stromal cell-derived factor- $1 \alpha$-mediated chemotaxis of human cord blood CD34+ progenitor cells," Journal of Immunology, vol. 169, no. 12, pp. 7000-7008, 2002.

[140] R. Sadir, A. Imberty, F. Baleux, and H. Lortat-Jacob, "Heparan sulfate/heparin oligosaccharides protect stromal cellderived factor-1 (SDF-1)/CXCL12 against proteolysis induced by CD26/dipeptidyl peptidase IV," The Journal of Biological Chemistry, vol. 279, no. 42, pp. 43854-43860, 2004.

[141] G. A. McQuibban, G. S. Butler, J.-H. Gong et al., "Matrix metalloproteinase activity inactivates the CXC chemokine stromal cell-derived Factor-1," The Journal of Biological Chemistry, vol. 276, no. 47, pp. 43503-43508, 2001.

[142] L.-K. Tsai, Y. Leng, Z. Wang, P. Leeds, and D.-M. Chuang, “The mood stabilizers valproic acid and lithium enhance mesenchymal stem cell migration via distinct mechanisms," Neuropsychopharmacology, vol. 35, no. 11, pp. 2225-2237, 2010.

[143] Y. Zhang, A. Foudi, J.-F. Geay et al., "Intracellular localization and constitutive endocytosis of CXCR4 in human CD34+ hematopoietic progenitor cells," Stem Cells, vol. 22, no. 6, pp. 1015-1029, 2004.

[144] A. Levoye, K. Balabanian, F. Baleux, F. Bachelerie, and B. Lagane, "CXCR7 heterodimerizes with CXCR4 and regulates CXCL12-mediated G protein signaling," Blood, vol. 113, no. 24, pp. 6085-6093, 2009.

[145] T. Tondreau, N. Meuleman, B. Stamatopoulos et al., "In vitro study of matrix metalloproteinase/tissue inhibitor of metalloproteinase production by mesenchymal stromal cells in response to inflammatory cytokines: the role of their migration in injured tissues," Cytotherapy, vol. 11, no. 5, pp. 559-569, 2009.

[146] A. De Becker, P. van Hummelen, M. Bakkus et al., "Migration of culture-expanded human mesenchymal stem cells through bone marrow endothelium is regulated by matrix metalloproteinase- 2 and tissue inhibitor of metalloproteinase3," Haematologica, vol. 92, no. 4, pp. 440-449, 2007.

[147] L.-K. Tsai, Z. Wang, J. Munasinghe, Y. Leng, P. Leeds, and D.M. Chuang, "Mesenchymal stem cells primed with valproate and lithium robustly migrate to infarcted regions and facilitate recovery in a stroke model," Stroke, vol. 42, no. 10, pp. 2932 2939, 2011.

[148] J. Lu, B. K. Teh, L. Wang et al., "The classical and regulatory functions of Clq in immunity and autoimmunity," Cellular and Molecular Immunology, vol. 5, no. 1, pp. 9-21, 2008.

[149] A. Jalili, L. Marquez-Curtis, N. Shirvaikar, M. Wysoczynski, M. Ratajczak, and A. Janowska-Wieczorek, "Complement Clq enhances homing-related responses of hematopoietic stem/ progenitor cells," Transfusion, vol. 50, no. 9, pp. 2002-2010, 2010.

[150] S.-C. Hung, R. R. Pochampally, S.-C. Hsu et al., "Short-term exposure of multipotent stromal cells to low oxygen increases their expression of CX3CR1 and CXCR4 and their engraftment in vivo," PLoS ONE, vol. 2, no. 5, article e416, 2007.

[151] L. Li and J. Jiang, "Regulatory factors of mesenchymal stem cell migration into injured tissues and their signal transduction mechanisms," Frontiers of Medicine in China, vol. 5, no. 1, pp. 33-39, 2011.

[152] J. Chen, R. Crawford, C. Chen, and Y. Xiao, “The key regulatory roles of the PI3K/Akt signaling pathway in the functionalities of mesenchymal stem cells and applications in tissue regeneration," Tissue Engineering B, vol. 19, no. 6, pp. 516-528, 2013.

[153] H. Liu, W. Xue, G. Ge et al., "Hypoxic preconditioning advances CXCR4 and CXCR7 expression by activating HIF-1 $\alpha$ in MSCs," Biochemical and Biophysical Research Communications, vol. 401, no. 4, pp. 509-515, 2010.

[154] C. H. Ryu, S. A. Park, S. M. Kim et al., "Migration of human umbilical cord blood mesenchymal stem cells mediated by stromal cell-derived factor-1/CXCR4 axis via Akt, ERK, and p38 signal transduction pathways," Biochemical and Biophysical Research Communications, vol. 398, no. 1, pp. 105-110, 2010.

[155] M. N. Lin, D. S. Shang, W. Sun et al., "Involvement of PI3K and ROCK signaling pathways in migration of bone marrow-derived mesenchymal stem cells through human brain microvascular endothelial cell monolayers," Brain Research, vol. 1513, pp. 1-8, 2013.

[156] Z. Bulj, S. Duchi, A. Bevilacqua et al., "Protein kinase B/AKT isoform 2 drives migration of human mesenchymal stem cells," International Journal of Oncology, vol. 42, no. 1, pp. 118-126, 2013.

[157] J. Xie, W. Wang, J. W. Si et al., "Notch signaling regulates CXCR4 expression and the migration of mesenchymal stem cells," Cellular Immunology, vol. 281, no. 1, pp. 68-75, 2013.

[158] M. . Krampera, J. Galipeau, Y. Shi, K. Tarte, L. Sensebe, and MSC Committee of the International Society for Cellular Therapy (ISCT), "Immunological characterization of multipotent mesenchymal stromal cells-the international society for cellular therapy (ISCT) working proposal," Cytotherapy, vol. 15, no. 9, pp. 1054-1061, 2013.

[159] A. M. Dimarino, A. I. Caplan, and T. L. Bonfield, "Mesenchymal stem cells in tissue repair," Frontiers in Immunology, vol. 4, article 201, 2013. 
[160] M. M. Lalu, L. McIntyre, C. Pugliese et al., "Safety of cell therapy with mesenchymal stromal cells (SafeCell): a systematic review and meta-analysis of clinical trials," PLoS One, vol. 7, no. 10, Article ID e47559, 2012.

[161] Y. Wang, Z.-b. Han, Y.-p. Song, and Z. C. Han, "Safety of mesenchymal stem cells for clinical application," Stem Cells International, vol. 2012, Article ID 652034, 4 pages, 2012.

[162] L. von Bahr, I. Batsis, G. Moll et al., "Analysis of tissues following mesenchymal stromal cell therapy in humans indicates limited long-term engraftment and no ectopic tissue formation," Stem Cells, vol. 30, no. 7, pp. 1575-1578, 2012.

[163] M. François, I. B. Copland, S. Yuan, R. Romieu-Mourez, E. K. Waller, and J. Galipeau, "Cryopreserved mesenchymal stromal cells display impaired immunosuppressive properties as a result of heat-shock response and impaired interferon- $\gamma$ licensing," Cytotherapy, vol. 14, no. 2, pp. 147-152, 2012. 


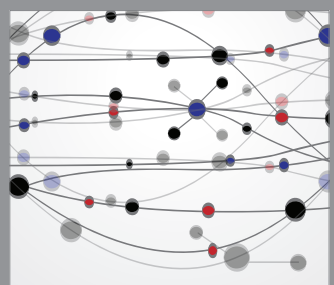

The Scientific World Journal
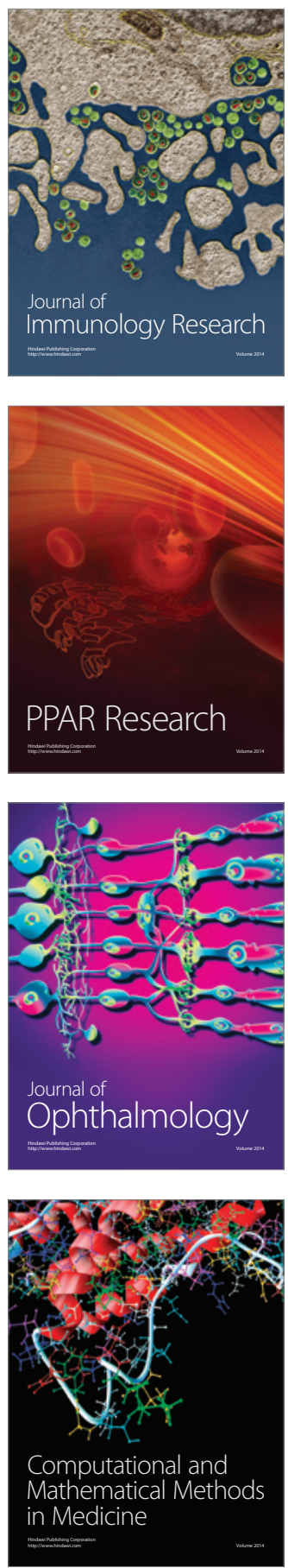

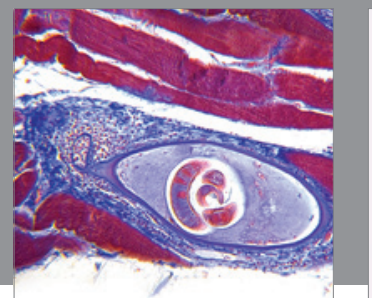

Gastroenterology

Research and Practice
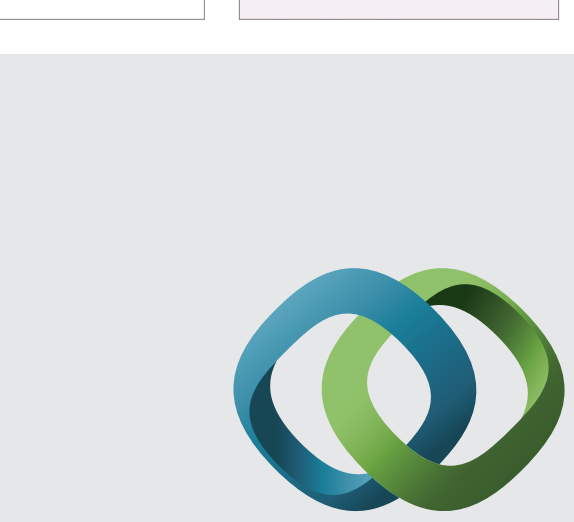

\section{Hindawi}

Submit your manuscripts at

http://www.hindawi.com
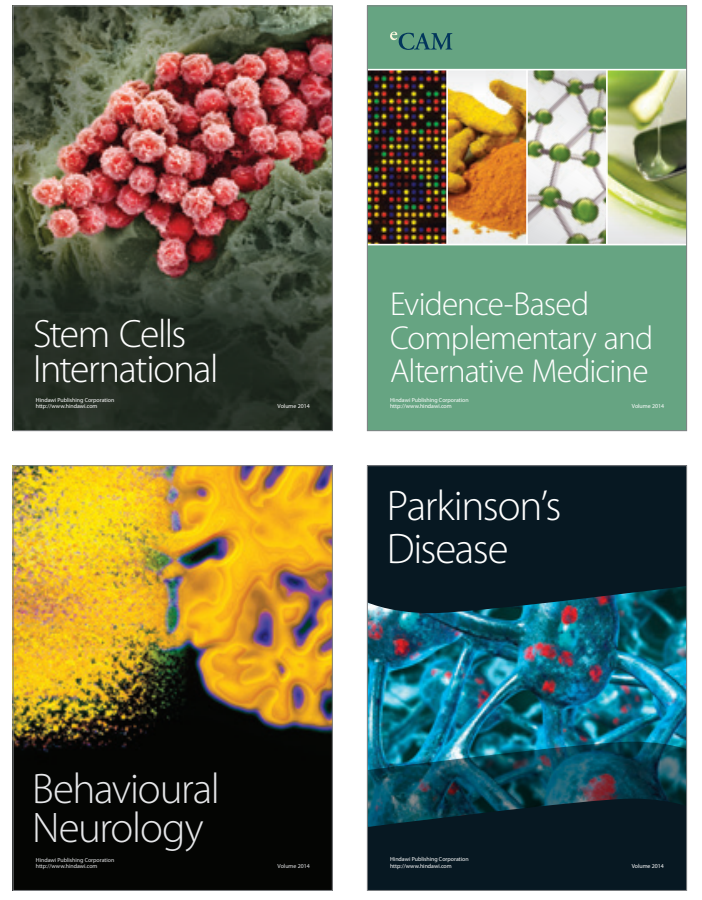
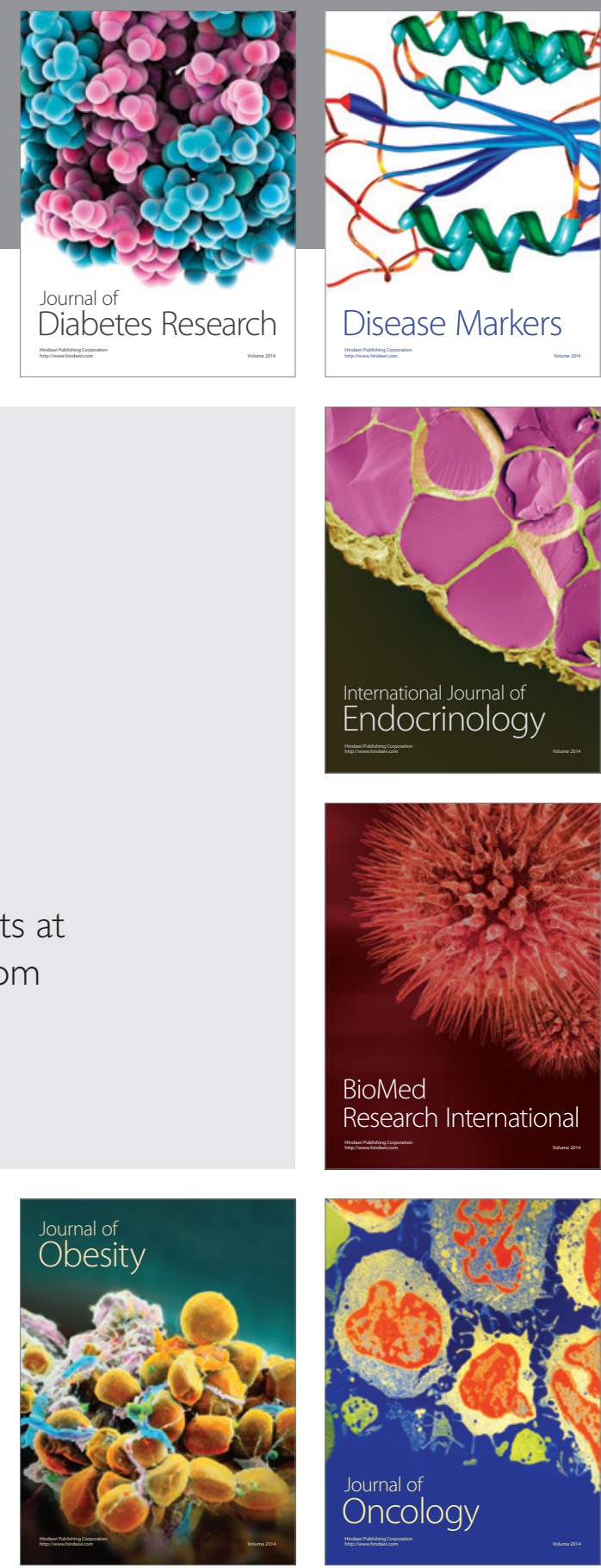

Disease Markers
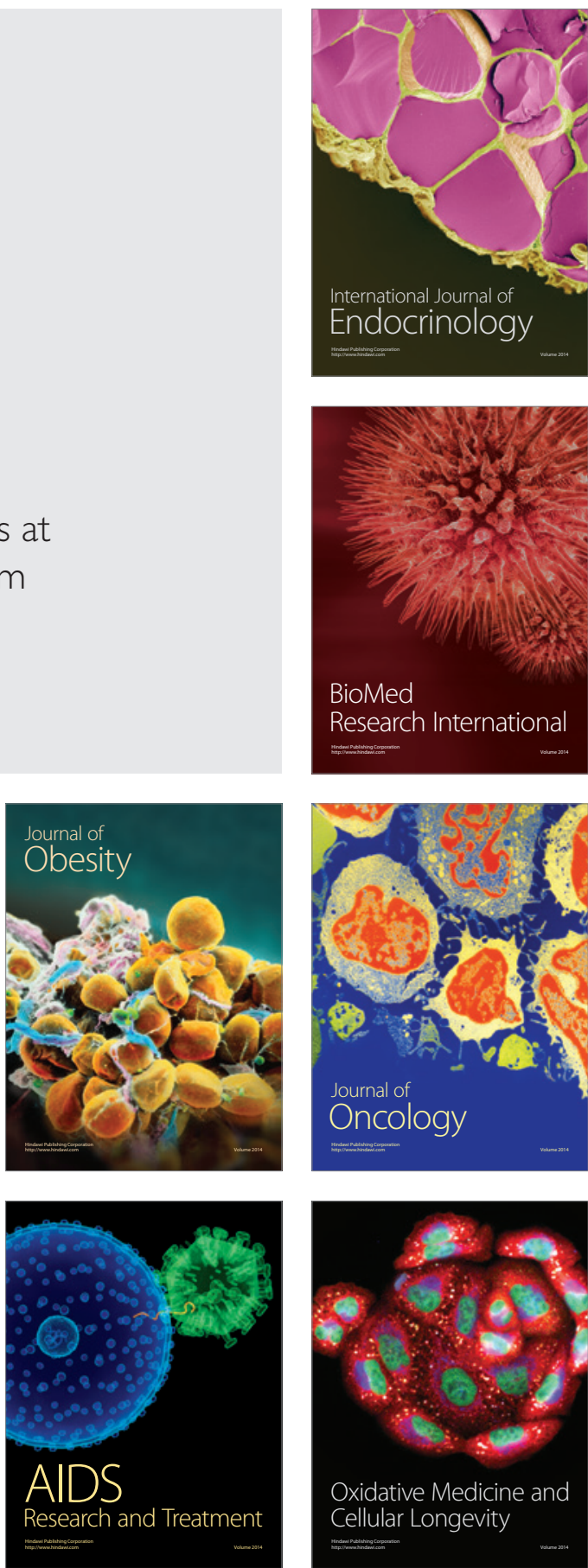